\title{
Impacts of Model Bias on the Climate Change Signal and Effects of Weighted Ensembles of Regional Climate Model Simulations: A Case Study over Southern Québec, Canada
}

\author{
Hyung-Il Eum, ${ }^{1}$ Philippe Gachon, ${ }^{2}$ and René Laprise ${ }^{2}$ \\ ${ }^{1}$ APEC Climate Center (APCC), 12 Centum 7-ro, Haeundae-gu, Busan 612-020, Republic of Korea \\ ${ }^{2}$ Étude et Simulation du Climat à l'Échelle Régionale (ESCER), University of Québec at Montreal, 201 Président Kennedy Avenue, \\ Montréal, QC, Canada H2X 3 Y7
}

Correspondence should be addressed to Hyung-Il Eum; hieum01@apcc21.org

Received 19 August 2015; Revised 27 October 2015; Accepted 17 November 2015

Academic Editor: Xiaofeng Li

Copyright @ 2016 Hyung-Il Eum et al. This is an open access article distributed under the Creative Commons Attribution License, which permits unrestricted use, distribution, and reproduction in any medium, provided the original work is properly cited.

\begin{abstract}
This study examined the impact of model biases on climate change signals for daily precipitation and for minimum and maximum temperatures. Through the use of multiple climate scenarios from 12 regional climate model simulations, the ensemble mean, and three synthetic simulations generated by a weighting procedure, we investigated intermodel seasonal climate change signals between current and future periods, for both median and extreme precipitation/temperature values. A significant dependence of seasonal climate change signals on the model biases over southern Québec in Canada was detected for temperatures, but not for precipitation. This suggests that the regional temperature change signal is affected by local processes. Seasonally, model bias affects future mean and extreme values in winter and summer. In addition, potentially large increases in future extremes of temperature and precipitation values were projected. For three synthetic scenarios, systematically less bias and a narrow range of mean change for all variables were projected compared to those of climate model simulations. In addition, synthetic scenarios were found to better capture the spatial variability of extreme cold temperatures than the ensemble mean scenario. These results indicate that the synthetic scenarios have greater potential to reduce the uncertainty of future climate projections and capture the spatial variability of extreme climate events.
\end{abstract}

\section{Introduction}

Climate change has significant effects on the natural (e.g., hydrologic systems) and social components (e.g., urban development) of regional systems $[1,2]$. Changes in extreme weather and climate events have particularly significant impacts and are among the most serious challenges for all human societies. In recent decades, an unprecedented number of extreme climate events have occurred, such as unusually hot days and nights, fewer unusually cold days and nights, and fewer frost days [3], while heavy rainfall has also become more frequent and intense [4]. In addition, more extreme and frequent floods and droughts are anticipated in the future $[5,6]$. All of these factors exert a major influence at regional scales, potentially increasing the risk of disaster for both human and environmental systems. Therefore or, feasible plausible regional climate scenarios are necessary to efficiently adapt to climate change and to mitigate the risk of disaster, especially when extreme weather and high impact climatic events are concerned. Confidence in projecting changes in the direction and magnitude of climate extremes depends on many factors, for example, the type of extreme, the region, and season, the amount and quality of observational data, the understanding of underlying processes, and the reliability of model simulations, especially at the regional scale [6].

Recently, numerous regional climate models (RCMs) have provided regionalized climate information to assess the hydrologic and environmental as well as the social and economic impacts of climate change (see the recent CORDEX initiative organized by the World Climate Research Program, http://www.cordex.org/). These RCMs are nested in atmosphere-ocean global climate models (AOGCMs) or 
global-scale reanalysis products. Because RCMs incorporate higher-resolution surface forcings (i.e., topography, land-sea contrast, land surface conditions, and other parameters), a large range of climate responses has been detected in previous studies, depending on the combination of RCMs/AOGCMs [7-9]. In particular, the reported temperature responses of the RCMs during winter are extremely variable due to snowalbedo feedbacks that are quasiabsent in AOGCMs as a result of their coarse horizontal resolution [10, 11]. The high and variable spatial resolutions of RCMs may therefore result in higher spatial and temporal variability in climate responses compared with those from AOGCMs, which also means potentially higher uncertainty in climate simulations derived from both RCMs and AOGCMs when changes in regional surface conditions are considered $[12,13]$.

An accurate assessment of confidence in future regional scale climate models from all available RCMs is essential to identify sources of uncertainty and thereby prevent erroneous analysis in climate change impact studies at regional scales $[14,15]$. Therefore, it is crucial to systematically assess the dependence of projected regional climate change signals on model bias at regional scales [16]. The presence of this dependence may be an important issue when applying an ensemble scheme to consider the uncertainty in combined multimodel simulations with weighting procedures, as the main assumption behind an ensemble scheme is that the climate responses (e.g., model bias) in a model during the past provide robust guidance on the likelihood of future responses.

In addition, we need to investigate a range of climate change signals to estimate the variability of multi-RCM/ AOGCM projections. The results of several carefully controlled comparison studies have been reported by the European Prediction of Regional Scenarios and Uncertainties for Defining European Climate Change Risks and Effects (PRUDENCE) [17], the ENSEMBLES project over the whole European region [8], and the recent North American Regional Climate Change Assessment Program (NARCCAP) [18]. These studies evaluated the accuracy of RCMs by comparing regional climate simulations with historical observed data and estimated the uncertainty of projected climate scenarios over all study regions (i.e., over Europe and the USA). In these studies, changes in mean values between the current and future periods were investigated to assess the uncertainty of future climate conditions as an indigenous response of RCM/ AOGCM combinations to emission scenarios. To extend these studies to southern Québec (Canada), we investigate a range of spatial and temporal changes in meteorological variables (i.e., daily precipitation and minimum and maximum temperatures $\left(T_{\min }\right.$ and $\left.T_{\max }\right)$ ) under one Special Report on Emissions Scenarios (SRES) emission scenario (A2). We compare climate change signals estimated by differences in both extreme (e.g., 90th percentile of daily precipitation, and the 10th and 90th percentiles of daily $T_{\min }$ and $T_{\max }$ ) and median (50th percentile) values between the reference (19711995) and future (2041-2065) RCM/AOGCM simulations.

A model-performance-based weighting scheme was successfully applied, and it demonstrated that model weighting might improve the average skill of climate projections [2, 1921]. Eum et al. [2, 22] applied a comprehensive weighting method that takes into account the skill of both RCMs and AOGCMs based on RCM/AOGCM performance. These studies formulated a cumulative density function (CDF) using a comprehensive weighting method based on the performance of RCM/AOGCM and RCM/Reanalysis combinations. Using a Monte Carlo simulation (MCS) technique, synthetic future scenarios were generated based on the CDFs and were compared with twelve RCM/AOGCM simulations and the ensemble mean to consider a range of climate change signals for each meteorological variable. More details are provided in [2]. As in the previous studies, we use twelve RCMs, the ensemble mean, and five synthetic future scenarios to investigate the intermodel correlation of changes in bias and the range of climate change signals. The focus of this study is on the following three factors: (1) the dependence of projected climate change signals on model bias at the regional scale; (2) a comparison of the performance of RCM/AOGCM simulations and their synthetic scenarios; and (3) a comparison of seasonal climate change signals for each RCM/ AOGCM and synthetic scenario, considering the median and extreme values.

The next section of the paper provides a description of the RCM/AOGCM simulation and scenarios generated based on weighting factors. The study area and reference-gridded observed datasets are presented in the subsequent section. The results section presents an intermodel correlation of the bias and climate change signal with the range of extreme and median values of climate change signals for each season and subregion within the study basin. In the summary and discussion section, we discuss our results and offer a general conclusion regarding the climate signals developed over the study area.

\section{RCM/AOGCM Simulations and Synthetic Scenarios}

This study used twelve RCM/AOGCM combinations released from NARCCAP (http://www.narccap.ucar.edu) and from the Data Access and Integration (DAI) project of Environment Canada (recently renamed the Canadian Climate Data and Scenarios portal, ccds-dscc.ec.gc.ca/). Table 1 presents the different versions of the Canadian Regional Climate Model (CRCM) $[23,24]$ according to initialization and domains at $45 \mathrm{~km}$ horizontal resolution provided by the Climate Scenarios and Services Group at Ouranos. CRCM4.1.1 has a smaller domain over Quebec (QC domain, $112 \times 88$ grid points) than other CRCMs, which incorporate a large domain covering North America (AMNO, $201 \times 193$ grid points).

NARCCAP released multiple high-resolution regional climate scenarios driven by multiple AOGCMs forced with the A2 emission scenario (e.g., [25]). In this study, we used multiple RCMs such as the CRCM4.2.0 and the Experimental Climate Prediction Version 2 (ECP2), MM5-PSU/NCAR mesoscale model (MM5I), Weather Research and Forecasting Models by US groups (WRFG), Regional Climate Model version 3 (RegCM3), and Hadley Regional Model 3 (HRM3) by European groups. ARPEGE (Action de Recherche Petite Echelle Grande Echelle) was developed by Meteo France to 
TABLE 1: Description of RCM/AOGCM combinations used in this study.

\begin{tabular}{|c|c|c|c|c|}
\hline Number & $\mathrm{RCM}$ & Driven by & Time window & Modeling center/source \\
\hline 1 & $\begin{array}{l}\text { CRCM4.2.3 } \\
\text { (aet) }\end{array}$ & $\begin{array}{l}\text { CGCM3 } \\
\text { 4th member }\end{array}$ & 1963-2001 & \multirow{3}{*}{$\begin{array}{l}\text { Ouranos/University of Quebec at } \\
\text { Montreal (UQAM)/Environmen } \\
\text { Canada }\end{array}$} \\
\hline 2 & $\begin{array}{l}\text { CRCM4.2.3 } \\
\quad(\mathrm{aev})\end{array}$ & $\begin{array}{l}\text { CGCM3 } \\
5 \text { th member }\end{array}$ & $2041-2070$ & \\
\hline 3 & $\begin{array}{l}\text { CRCM4.1.1 } \\
\text { (QC domain) }\end{array}$ & $\begin{array}{l}\text { CGCM3 } \\
\text { 4th member }\end{array}$ & $\begin{array}{l}1968-2000 \\
2041-2070\end{array}$ & \\
\hline 4 & CRCM4.2.0 & \multirow{2}{*}{$\begin{array}{l}\text { CGCM3 } \\
4 \text { th member }\end{array}$} & $\begin{array}{l}1968-2000 \\
2041-2070\end{array}$ & \multirow{8}{*}{$\begin{array}{l}\text { NARCCAP } \\
\text { (http://www.narccap.ucar.edu/) }\end{array}$} \\
\hline 5 & RCM3 & & $\begin{array}{l}1968-2000 \\
2041-2065\end{array}$ & \\
\hline 6 & CRCM4.2.0 & & $\begin{array}{l}1968-1998 \\
2041-2070\end{array}$ & \\
\hline 7 & MM5I & CCSM & $\begin{array}{l}1968-1999 \\
2041-2070\end{array}$ & \\
\hline 8 & WRFG & & $\begin{array}{l}1968-1999 \\
2041-2070\end{array}$ & \\
\hline 9 & RCM3 & \multirow[b]{2}{*}{ GFDL } & $\begin{array}{l}1968-2000 \\
2041-2070\end{array}$ & \\
\hline 10 & $\mathrm{ECP} 2$ & & $\begin{array}{l}1968-2001 \\
2041-2070\end{array}$ & \\
\hline 11 & HRM3 & HadCM3 & $\begin{array}{l}1968-2000 \\
2041-2070\end{array}$ & \\
\hline 12 & ARPEGE & ARPEGE & $\begin{array}{l}1961-2001 \\
2041-2070\end{array}$ & Ouranos/Météo-France \\
\hline
\end{tabular}

simulate the European climate [26], and the Climate Scenarios and Services Group at Ouranos produced a regional climate simulation over North America.

Five driving AOGCMs were used in this study: (1) the NCAR Community Climate System Model: CCSM [27]; (2) the third Canadian Global Climate Model: CGCM3 [28]; (3) the Geophysical Fluid Dynamics Laboratory: GFDL [29]; (4) the Hadley Centre Coupled Model, version 3: HadCM3 [30]; and (5) the ARPEGE global model version 3 [31]. Note that not all RCMs incorporated the five driving AOGCM simulations due to the limited RCM/AOGCM data pool. For example, HRM3 is driven only by HadCM3, and GFDL is used in RCM3 and ECP2 simulations (see Table 1). However, this study includes an identical CRCM version (CRCM4.2.0) with different driving AOGCM conditions (CGCM3 and CCSM), which enabled us to assess the effects of different boundary forcings according to the variability in RCM/AOGCM simulations.

Eum et al. [2] suggested the following comprehensive weighting factor that comprises the RCM and AOGCM weighting factors and a multiplication factor:

$$
W_{k}=w_{i}^{\mathrm{RCM}} \times w_{j}^{\mathrm{AOGCM}} \quad w=\prod_{m} f_{m}^{n_{m}}
$$

where $W_{k}$ is the comprehensive weighting factor of the $k$ th $\mathrm{RCM} / \mathrm{AOGCM}$ combination; $w_{i}^{\mathrm{RCM}}$ is a weighting factor for the $i$ th RCM calculated from the performance of RCM/Reanalysis data; $w_{j}^{\text {AOGCM }}$ is a weighting factor of the $j$ th AOGCM estimated from the average performance of RCM simulations driven by the same AOGCM; and $w$ is a combined weighting factor [8] consisting of a performance metric $m\left(f_{m}\right)$ and an exponent $n_{m}$. This study evaluated five performance metrics: relative absolute mean error, annual variability, spatial pattern, extreme events, and multidecadal trend [2]. If reanalysis data was used instead of an AOGCM in the comprehensive weighting factor, we assumed that $w_{j}^{\text {AOGCM }}$ would be 1.0 because the reanalysis data forced by observed data through state-of-the-art assimilation techniques, for example, National Centers for Environmental Prediction/National Center for Atmospheric Research (NCEP/NCAR) [32] and European Centre for Medium-Range Weather Forecasts (ECMWF-ERA40) [33], can be considered as near-best-fit models, although some biases still exist. The exponent $n_{m}$ represents the relative importance of the performance metrics and may significantly affect the performance of the weighting factor. Eum et al. [2] used the differential evolution (DE) optimization scheme [34] to determine an optimal relative importance and then compared it with the equal relative importance considering the skills of RCMs and AOGCMs, which were referred to as DE (RCM/AOGCM) and EQ (RCM/AOGCM), respectively. More details on the weighting factor and its use can be found in [2].

Using the CDFs formulated with DE (RCM/AOGCM) and EQ (RCM/AOGCM) and simple equal probability (SEP) that assigned equal weighting to all RCMs, we generated synthetic scenarios with the MCS technique over the common time windows given in Table 1: hindcast (25 years from 1971 to 1995 ) and future (25 years from 2041 to 2065). In addition, we used an ensemble mean scenario that simply averaged the simulations from all RCM/AOGCMs. Therefore, this study 


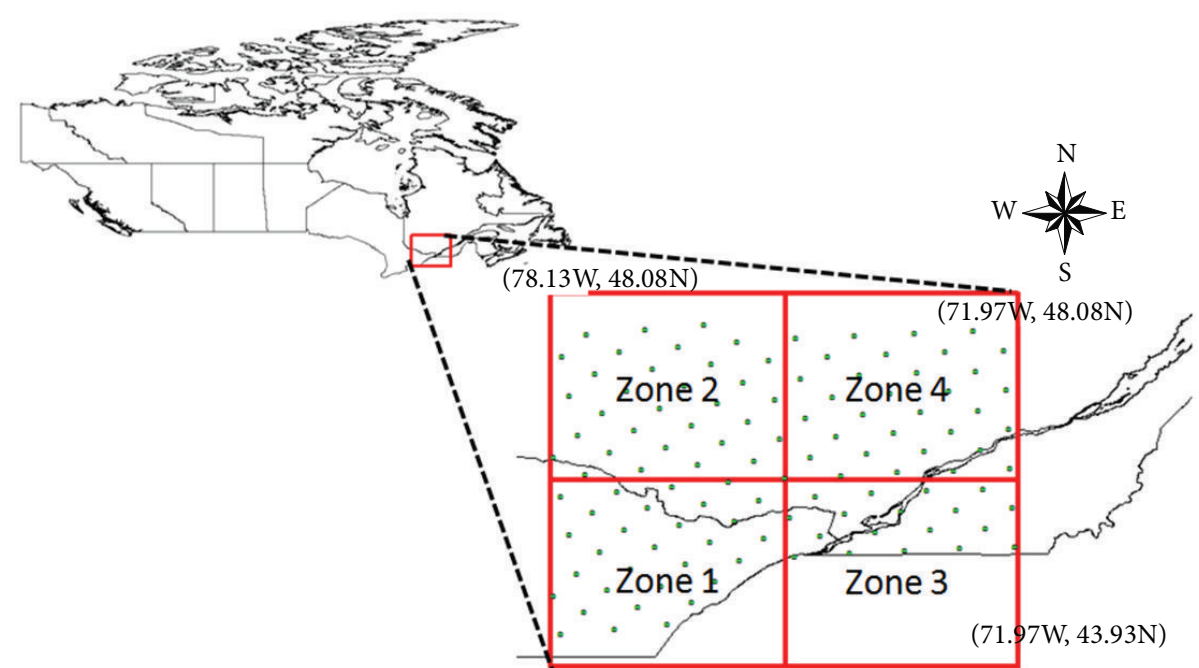

(78.13W, 43.93N)

$(\mathrm{km})$

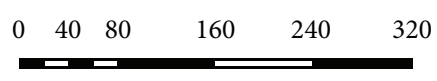

Grid points

- Boundaries

Figure 1: Study area over Québec and Ontario Provinces, Canada.

investigated the climate signals from 16 simulations (i.e., 12 RCM/AOGCM simulations and four synthetic scenarios).

\section{Application}

3.1. Study Area. As a follow-up case study of previous climate change studies $[2,22]$, we selected the Southern Quebec and Ontario regions in Canada bounded by $43.93-48.08^{\circ} \mathrm{N}$ and $71.97-78.13^{\circ} \mathrm{W}$ (Figure 1). This area, which is covered by 113 grid points on the CRCM $45-\mathrm{km}$ polar stereographic (PS) grid, was divided into four subzones to investigate the spatial variability of model performance, as significant differences across these subzones were obtained from the RCM runs for both the current and the future simulated periods [2].

The reference-gridded observed datasets of [35] were used to calculate model bias at each grid point. The gridded data sets provided a daily time series of precipitation and temperature $\left(T_{\min }\right.$ and $\left.T_{\max }\right)$ derived from a Canada-wide spatial model ( $10-\mathrm{km}$ gridded climate dataset) using data from Environment Canada’s 7,514 stations from 1961 to 2003; the number of stations active for a given year ranged from 2,000 to 3,000 for precipitation and from 1,500 to 2,200 for temperature. All gridded climate data (all RCMs given in Table 1, as well as the gridded observed data of [35]) were interpolated to the CRCM $45 \mathrm{~km}$ PS grid to facilitate comparison of model performances (see [22]).

3.2. Bias and Climate Change Signal. We calculated the bias and climate change signals for all climate scenarios at each grid point and then aggregated them over the four subregions to analyze the relation between bias and climate change signals for each subregion. Bias was calculated from the differences between simulated and gridded observed data [35], and the climate change signal was calculated by the difference between the mean and extreme values for the future (2041-2065) and the reference (1971-1995) periods from RCM/AOGCMs or synthetic simulations. The variables considered were daily precipitation, $T_{\min }$, and $T_{\max }$, which are key input data for environmental and hydrologic modeling. The analysis was conducted on the median and extremes, that is, the 90th percentile of daily precipitation, the 10th and 90th percentiles of daily $T_{\min }$ and $T_{\max }$, and the 50th percentiles of all variables.

\section{Results and Discussion}

4.1. Correlation between Bias and the Climate Change Signal. Figures 2 and 3 show spatial maps of the bias and the climate change signal for the three variables (mean values averaged over the $12 \mathrm{RCM} / \mathrm{AOGCM}$ simulations) during summer and winter, respectively. These maps were initially used to examine whether a regional pattern of bias versus signal characteristics existed within the study area. For precipitation, there was a considerable negative relationship between bias and climate change signal in the study area. Grid points where high biases were identified, in particular over the southeast area, projected a low climate change signal in precipitation. In summer, for both $T_{\min }$ and $T_{\max }$, a general cold bias was apparent over the whole region and was more pronounced in the south along the St. Lawrence valley and in the east. These large biases generally corresponded to the location of small climate change signals, with larger signals found in the southwestern region. These results may have been induced by 


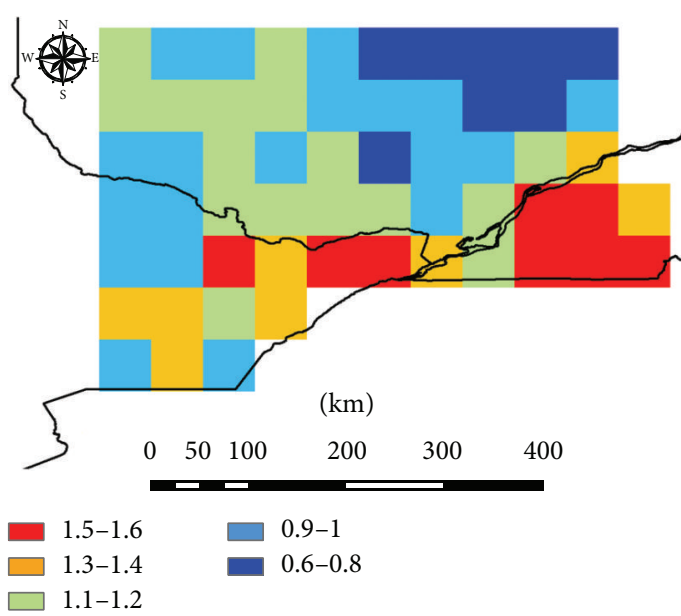

(a) Bias of precipitation

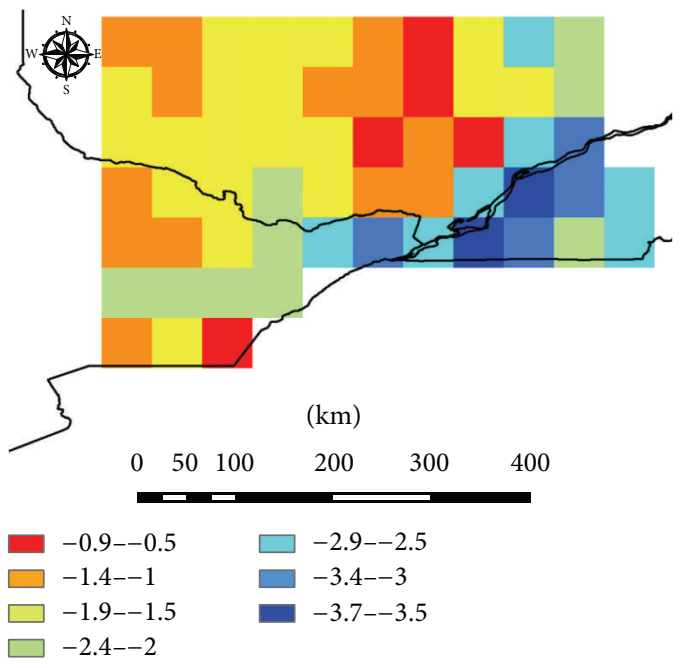

(c) Bias of minimum temperature

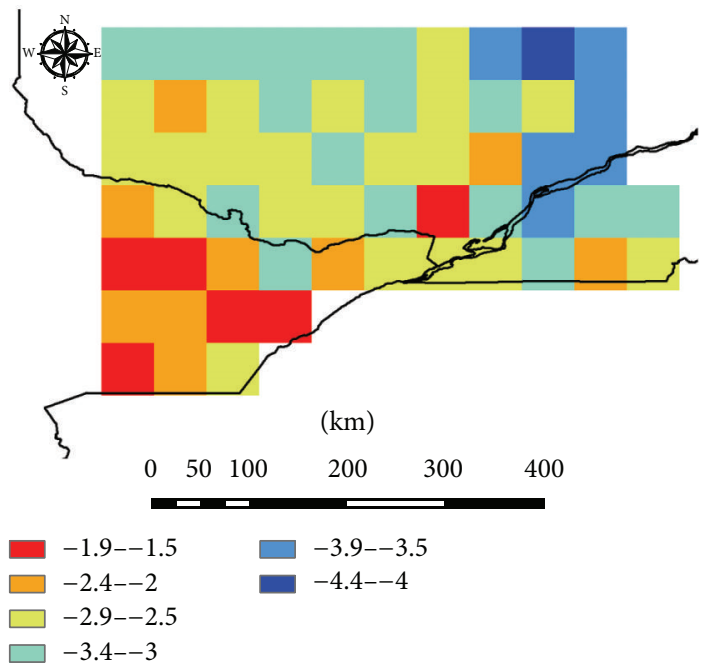

(e) Bias of maximum temperature

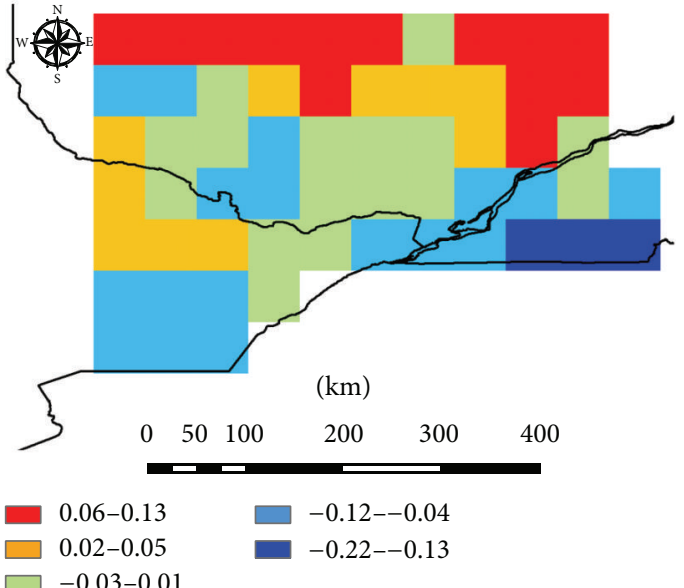

(b) Signal of precipitation

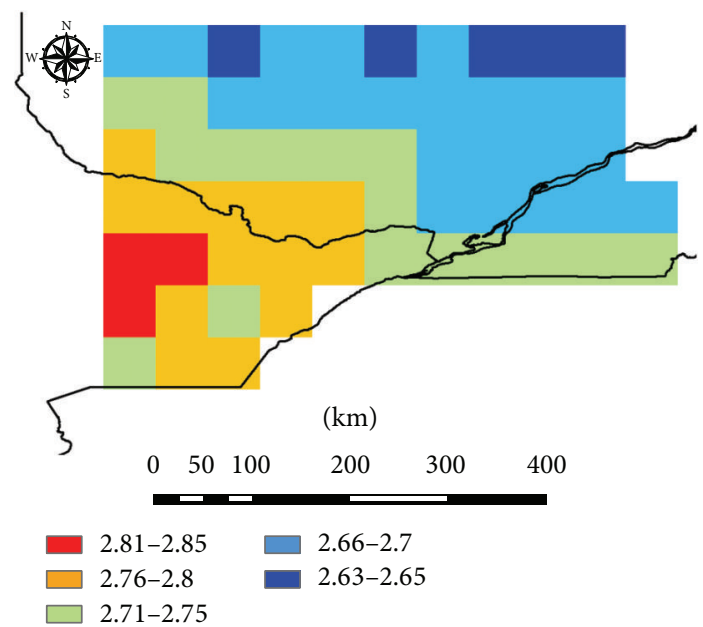

(d) Signal of minimum temperature

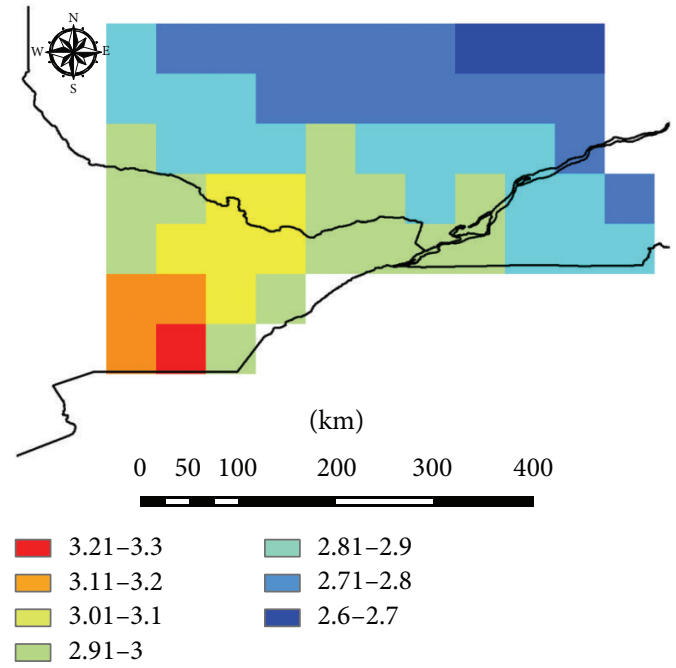

(f) Signal of maximum temperature

FIGURE 2: Spatial map of intermodel biases and climate change signals averaged for all RCM/AOGCMs' simulations during summer season for precipitation (in $\mathrm{mm} / \mathrm{d}$ ) and minimum and maximum temperatures (in ${ }^{\circ} \mathrm{C}$ ). 

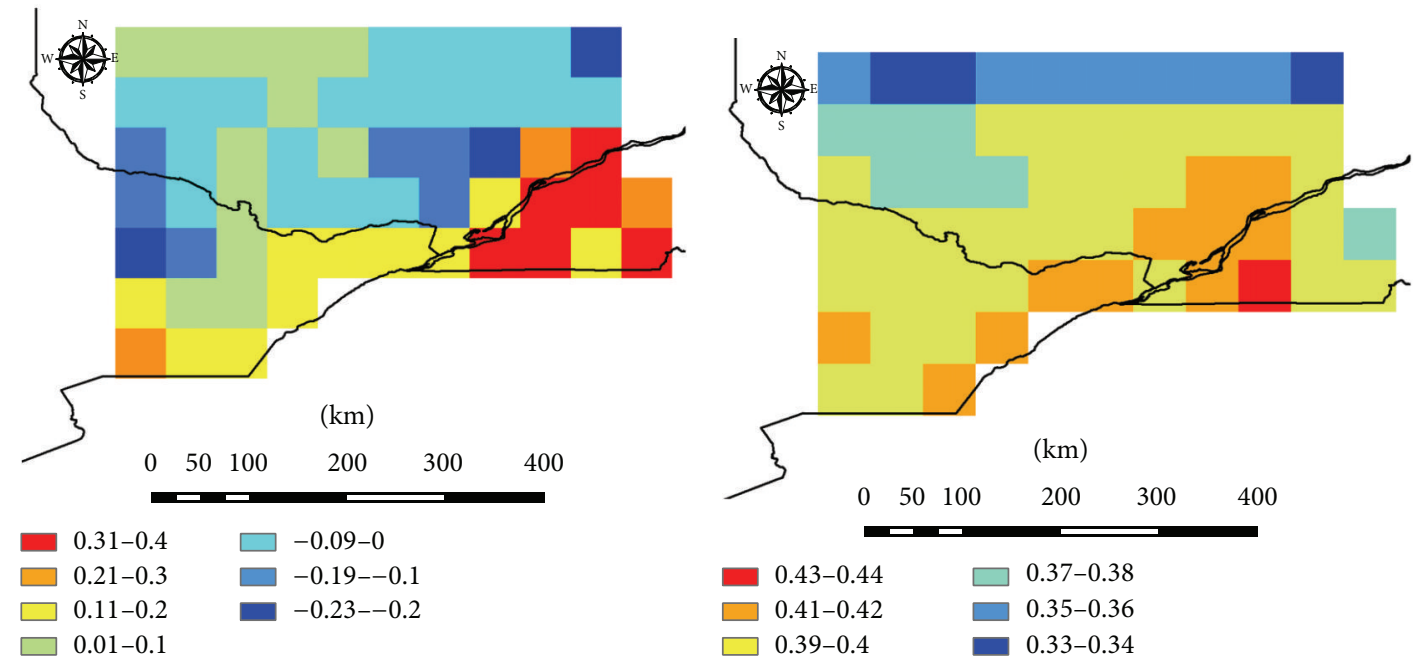

(a) Bias of precipitation

(b) Signal of precipitation

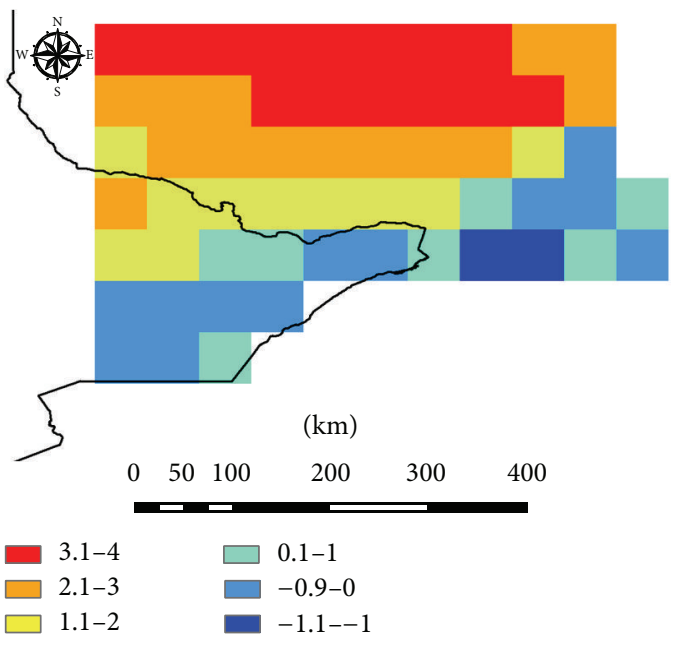

(c) Bias of minimum temperature

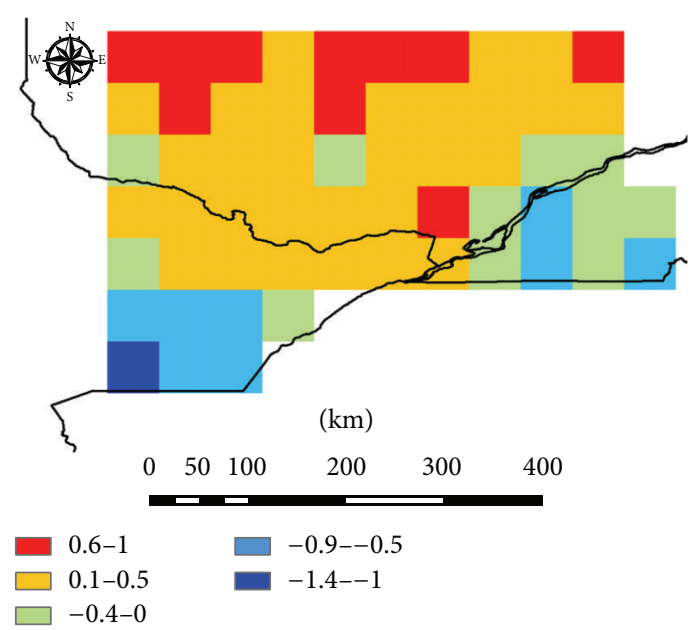

(e) Bias of maximum temperature

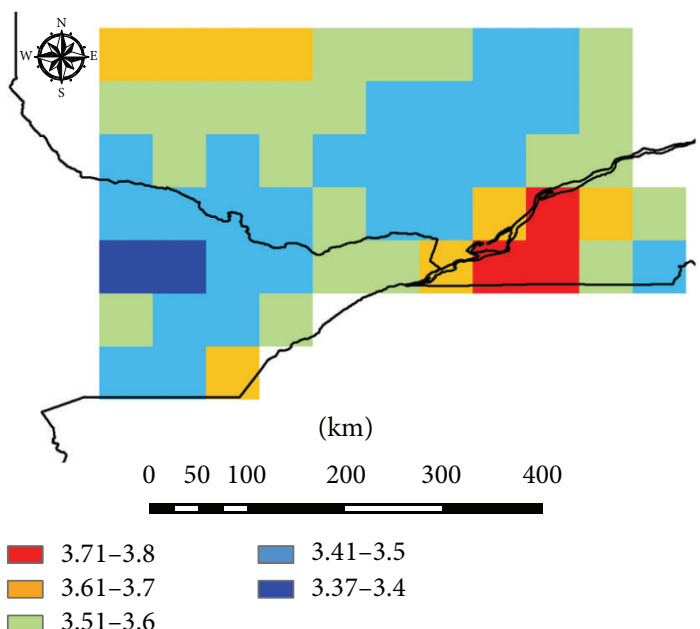

(d) Signal of minimum temperature

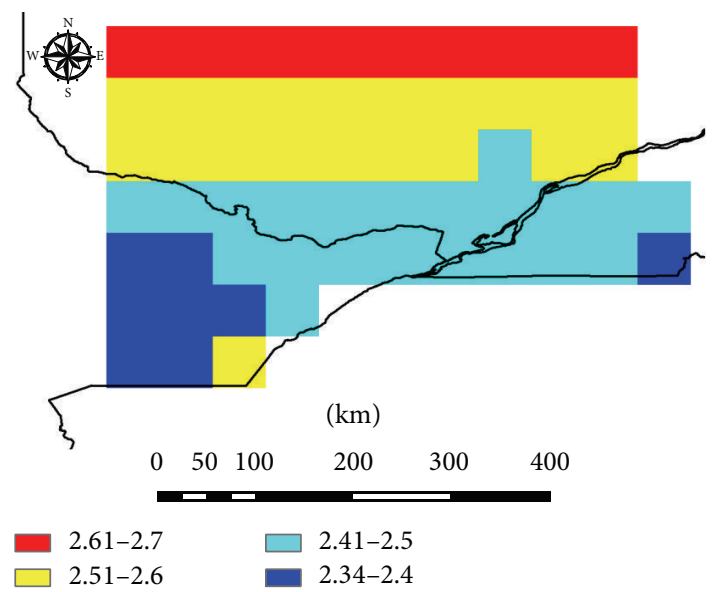

(f) Signal of maximum temperature

FIgURE 3: Same as Figure 2 but for the winter season. 
TABLE 2: Intermodel correlation between simulated change and bias for seasonal mean precipitation and temperatures. Precipitation (PPT), $T_{\min }$, and $T_{\max }$ represent precipitation, minimum temperature, and maximum temperature, respectively. Bold font in correlation coefficient represents the case in which the intermodel correlation is significant at the $90 \%$ confidence level (absolute values above |0.497|). Each subregion or zone (from 1 to 4) represents each subarea (SW, NW, SE, and NE, resp.) defined in Figure 1.

\begin{tabular}{|c|c|c|c|c|c|c|c|c|c|}
\hline \multirow{2}{*}{ Zone } & \multirow{2}{*}{ Season } & \multicolumn{3}{|c|}{ Mean change versus bias } & \multicolumn{3}{|c|}{ 90th percentile change versus Bias } & \multicolumn{2}{|c|}{ 10th percentile change versus bias } \\
\hline & & $\mathrm{PPT}(\mathrm{mm} / \mathrm{d})$ & $T_{\min }\left({ }^{\circ} \mathrm{C}\right)$ & $T_{\max }\left({ }^{\circ} \mathrm{C}\right)$ & $\mathrm{PPT}(\mathrm{mm} / \mathrm{d})$ & $T_{\min }\left({ }^{\circ} \mathrm{C}\right)$ & $T_{\max }\left({ }^{\circ} \mathrm{C}\right)$ & $T_{\min }\left({ }^{\circ} \mathrm{C}\right)$ & $T_{\max }\left({ }^{\circ} \mathrm{C}\right)$ \\
\hline \multirow{4}{*}{1} & Spring & 0.55 & -0.53 & 0.42 & 0.36 & -0.01 & -0.36 & -0.62 & -0.64 \\
\hline & Summer & -0.30 & -0.87 & -0.61 & -0.09 & -0.84 & -0.76 & -0.84 & -0.80 \\
\hline & Autumn & 0.18 & -0.56 & -0.18 & -0.23 & -0.33 & -0.78 & -0.76 & -0.47 \\
\hline & Winter & -0.17 & -0.86 & -0.82 & -0.10 & -0.90 & -0.33 & -0.44 & -0.57 \\
\hline \multirow{4}{*}{2} & Spring & 0.64 & -0.68 & 0.43 & 0.79 & -0.08 & -0.42 & -0.61 & -0.64 \\
\hline & Summer & -0.38 & -0.88 & -0.76 & -0.18 & -0.74 & -0.71 & -0.78 & -0.87 \\
\hline & Autumn & -0.26 & -0.67 & -0.24 & -0.38 & -0.25 & -0.51 & -0.59 & -0.54 \\
\hline & Winter & -0.35 & -0.87 & -0.85 & -0.48 & -0.91 & -0.28 & -0.46 & -0.60 \\
\hline \multirow{4}{*}{3} & Spring & 0.15 & -0.65 & -0.41 & -0.32 & -0.06 & -0.33 & -0.57 & -0.47 \\
\hline & Summer & -0.50 & -0.35 & -0.19 & -0.27 & -0.75 & -0.79 & -0.80 & -0.87 \\
\hline & Autumn & 0.19 & 0.13 & 0.27 & -0.11 & -0.33 & -0.71 & -0.67 & -0.54 \\
\hline & Winter & -0.21 & -0.85 & -0.83 & -0.39 & -0.89 & -0.30 & -0.45 & -0.59 \\
\hline \multirow{4}{*}{4} & Spring & 0.55 & -0.72 & 0.28 & 0.48 & -0.01 & -0.38 & -0.59 & -0.51 \\
\hline & Summer & -0.37 & -0.87 & -0.76 & -0.01 & -0.77 & -0.70 & -0.76 & -0.88 \\
\hline & Autumn & 0.17 & -0.58 & -0.24 & -0.04 & -0.26 & -0.46 & -0.55 & -0.49 \\
\hline & Winter & -0.33 & -0.87 & -0.87 & -0.46 & -0.91 & -0.26 & -0.44 & -0.60 \\
\hline
\end{tabular}

the relatively coarse-scale resolution, which may have caused some systematic errors over complex topography and heterogeneous surface conditions, especially in the south near the St. Lawrence valley. There may have been low level land and a river in a grid, but the RCM simulated climate conditions in the grid as either land or a river (also with a smoother topographic effect in the RCM compared to the real physiographic features), which may affect both biases and climate signals for all variables in the south near the St. Lawrence valley. Recent results over this area [36] and over Europe (e.g., over the UK in [37]) have revealed that the added value from higherresolution models when modeling very fine local-mesoscale climate patterns over the inner domain, including the diurnal variations in temperature and winds and the effect of wind channeling (which affects the temperature advection), is crucial to decreasing the systematic biases in local climatology. In winter, warm biases for both $T_{\min }$ and $T_{\max }$ were found in the north, and cold biases were found in the southwest and southeast in summer. In such cases, the signals were slightly higher/lower in the north/south where warm/cold biases were apparent, along with a clear warming trend in $T_{\min }$ (but not $T_{\max }$ ), which was not apparent in summer.

In addition to the intermodel averaged bias and climate change signals of mean values across the study area, bias defined by the spatially averaged differences between simulated and gridded observed data for each subregion was calculated for each RCM/AOGCM combination with regard to both the mean and the extreme of daily $T_{\min }, T_{\max }$, and precipitation. In this way, the corresponding mean spatial climate change signals were calculated. Using all of the RCM/ AOGCM simulations, we calculated the intermodel Pearson's correlation between the bias and climate change signals for each season and subzone (as presented in Figure 1). Table 2 shows the intermodel correlation between the simulated climate signal and bias for precipitation and temperature fields, with the bold font representing the cases where the intermodel correlation was significant at the $90 \%$ confidence level (i.e., above $|0.497|)$. A significant correlation indicates that the model bias is linearly linked to the projected climate change signal of mean and extreme values for both a season and subregion. Note that the bias and the signal were calculated based on spatially averaged values over each subregion for each of the 12 AOGCM/AOGCM simulations, which provided 12 pairs of bias and signal values for the calculation of intermodel correlation.

For precipitation, only 4 of the 16 cases had a significant intermodel correlation between the mean change and bias in spring. In addition, only one case had a significant intermodel correlation at the 90th percentile in spring in subzone 2 , indicating that the linear dependency of the climate change signal on the model bias for both mean and extreme values of precipitation was not significant, except in spring. These results suggest that the precipitation projections might be mainly affected by emission scenarios or large-scale boundary forcings from AOGCMs and by local effects such as topography and local convection and their systematic influences on spatial biases over most of the study area in spring. In other seasons, biases and forcing factors were randomly distributed, with no clear link between bias features and climate signals. This means that the large-scale flow from AOGCMs dominated the regional climate responses during most of the year, particularly over the Great Lakes/St. 
Lawrence valley. This is also in line with a recent study over the same area [38], which showed that the largest source of uncertainty in summer or winter simulated (RCM) precipitation originated from the AOGCM selection, especially for heavy rainfall and along the St. Lawrence valley, which systematically exhibited a higher uncertainty value.

For $T_{\min }$, there were prominent negative correlations between the mean change and bias in 14 cases (87.5\%), implying that the RCMs with a higher positive bias (overestimation of observed $T_{\min }$ values) were likely to project a lower mean change and vice versa. Remarkably, the correlations between large extreme changes (i.e., 90th percentile of $T_{\min }$ ) and bias were mainly significant only for summer and winter in all subregions, whereas in most cases, the correlations of cold extreme changes (10th percentile of $T_{\min }$ ) with bias were significant except in winter. Such results indicate that the extreme minimum temperature (biases and climate change signals) for all seasons may be significantly and systematically affected by local or regional physical processes (e.g., topography and surface conditions), while depending mainly on the RCM/AOGCM sensitivity over the model domain rather than model bias for spring and autumn at the warm extreme (90th percentile) and for winter at the cold extreme (10th percentile). This also reflects the strong or systematic influences of surface conditions through spring to autumn both on the mean values of $T_{\min }$ and on the cold extremes of $T_{\min }$ from the proper diabatic fluxes, especially during thaw and frost periods in spring and autumn, and during the storage of heat within the soil in summer.

For $T_{\max }$, the correlation between the mean change and model bias was also significant only in summer and winter, whereas the correlation between the 90th percentile $T_{\max }$ change and bias was significant mainly in summer and autumn (except for subzone 4). The relationship between bias and the climate change signal of the 90th percentile $T_{\max }$ during winter was not significant because heat waves are a large-scale forcing derived from large-scale patterns such as the El Niño Southern Oscillation (ENSO), Pacific Decadal Oscillation (PDO), and blocking events over the eastern Pacific, among other climate phenomena (e.g., [39]). In winter, the warm extreme of the $T_{\max }$ climate change signal was mainly affected by the boundary conditions of the AOGCMs, which provided large-scale patterns rather than systematic biases in RCMs. However, in $87.5 \%$ of all cases, there were significant negative correlations between the 10th percentile change and bias, suggesting a quasisystematic link between climate change signals and bias for the cold extreme of $T_{\max }$. In summary, during summer, climate change signals significantly depended on the model bias in all subzones for both mean seasonal $T_{\min }$ and $T_{\max }$, as well as for their warm and cold extremes (i.e., their 10th and 90th percentiles). During winter, the situation was similar, although the dependence was only significant for the 10th percentile of $T_{\max }$ and 90th percentile of $T_{\min }$ climate change signals. In spring and autumn, the regional warm extreme (i.e., the 90th percentile) was affected mainly by the RCM/AOGCM sensitivity over the model domain, but it was still correlated with the bias for the cold extremes of $T_{\max }$ and $T_{\min }$ (10th percentiles). Hence, the dependence of moderate temperature changes on model bias, that is, the mean change in $T_{\min }$ and the 10th percentile change in $T_{\max }$, was significant in all seasons within the study area.

4.2. Comparison of RCM/AOGCM and Synthetic Simulation Performance. Figure 4 shows scatter plots of the intermodel and synthetic data mean changes versus bias for precipitation, $T_{\min }$, and $T_{\max }$. Because the differences in the relations between mean change and bias in all subzones were insignificant, the mean change and bias in Figure 4 were spatially averaged over the study area. Although we investigated the intermodel bias and mean changes for all seasons, only the results for summer and winter are shown here for brevity, as the majority of significant correlations (i.e., mean change versus bias) among model runs were found for these two seasons, as suggested in Table 2. All of the trend lines for both precipitation and temperature changes were in inverse proportion to bias, with a negative correlation. In addition, the four synthetic scenarios represented by red color (ensemble mean from $12 \mathrm{RCM} / \mathrm{AOGCM}$ simulations, DE (RCM/AOGCM), EQ (RCM/AOGCM), and SEP) systematically showed less bias and a narrow range of mean change and bias for all variables. CRCM423(AEV)_CGCM3 substantially overestimated the precipitation amount during both summer and winter. However, the effect of this large bias was not significant on the climate change signals, as reflected in Table 2. CRCM4.2.3 had a much lower bias when it was driven by the other members of the CGCM3 model group (i.e., AET simulation with the 4th CGCM3 member versus the AEV-5th CGCM3 member), indicating a substantial effect from members of the same AOGCM on RCM accuracy, as well as on the uncertainties in the climate change signal. For both $T_{\min }$ and $T_{\max }$, most RCM/AOGCM simulations were underestimated in summer and overestimated in winter, suggesting that the RCM/AOGCM simulations considered in this study were systematically biased in both seasons. In particular, the HRM3_HadCM3 substantially underestimated both temperatures in summer but overestimated them in winter. In addition, the scatter plots in winter had steeper slopes, a wider range of biases, and higher $R^{2}$ values for the trend line compared with those in summer, indicating a stronger correlation between model bias and mean change in winter, with a higher uncertainty in $T_{\min }$ projections in winter. The synthetic scenarios were also clearly less biased in winter with more consensual climate change signals, falling near the middle of the range of climate signals (i.e., reduced uncertainties from both DE and EQ simulated values) than the RCM/AOGCM raw outputs for all variables. In addition, DE (RCM/AOGCM) and EQ (RCM/AOGCM) projected higher climate change signals than the ensemble mean, especially for precipitation (and $T_{\min }$, to a lesser extent) because the performances of both synthetic scenarios depended on the accuracy of each RCM/AOGCM in the form of the weighting factor, whereas the ensemble mean projected a more conservative signal, which strongly depended on model run outliers and/or the spread of all simulated values.

Figures 5 and 6 show strong and systematic correlations between the cold extreme and warm extreme climate change signals of $T_{\min } / T_{\max }$ and their corresponding biases for 


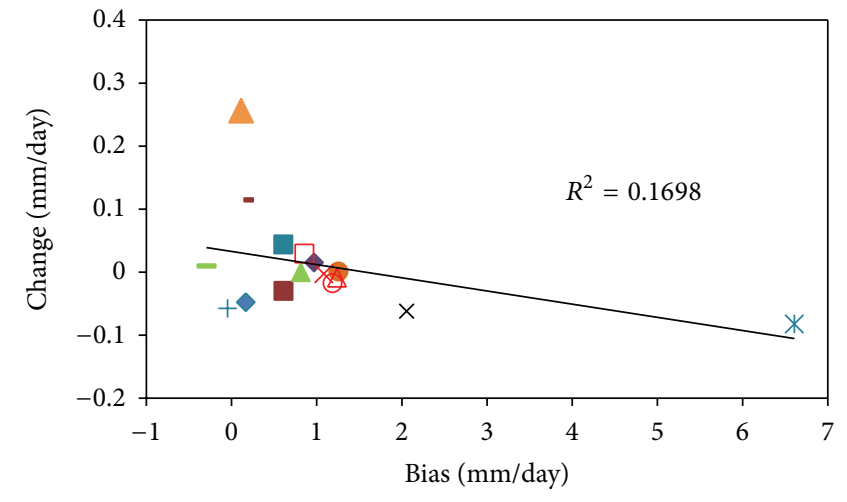

(a) Summer (precipitation)

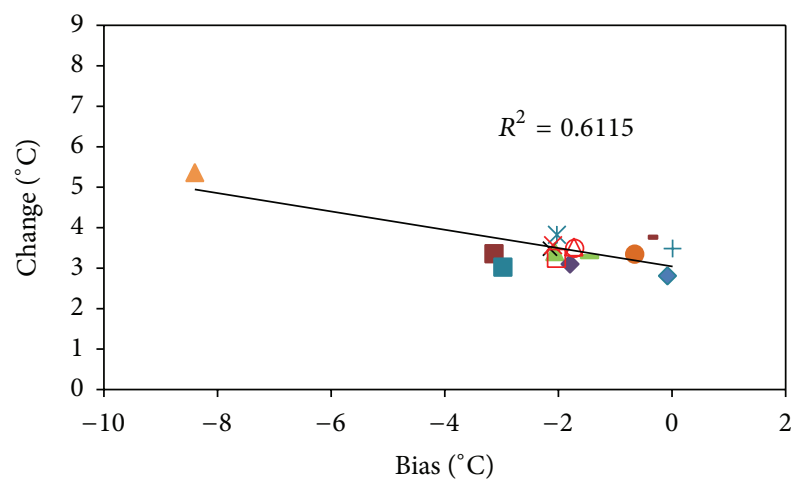

(c) Summer $\left(T_{\min }\right)$

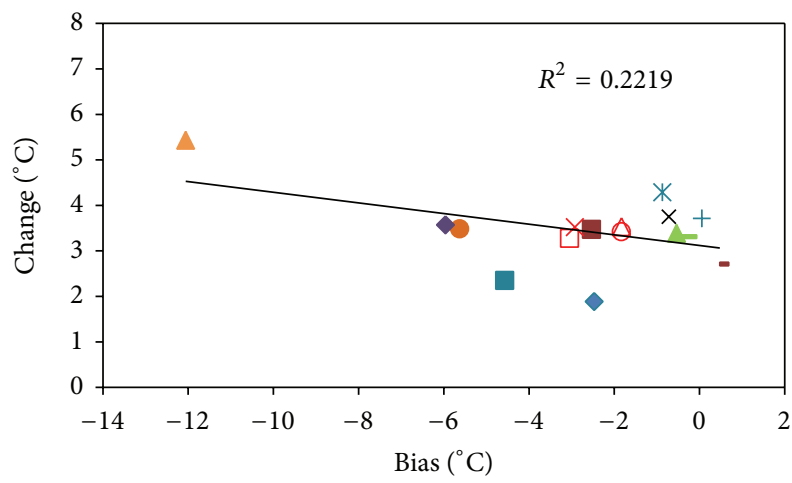

$\begin{array}{ll}\bullet \text { ARPEGE } & \circ \text { EQ (RCM/AOGCM) } \\ + \text { CRCM420_CCSM } & \times \text { CRCM423(AET)_CGCM3 } \\ \times \text { Ensemble_mean } & \bullet \text { RCM3_GFDL } \\ \square \text { CRCM420_CGCM3 } & \square \text { SEP } \\ - \text { MM5I_CCSM } & * \text { CRCM423(AEV)_CGCM3 } \\ \triangle \text { DE (RCM/AOGCM) } & \square \text { ECP2_GFDL } \\ \triangle \text { CRCM411QC_CGCM3 } & \bullet \text { RCM3_CGCM3 } \\ - \text { WRFG_CCSM } & \text { HRM3_HadCM3 }\end{array}$

(e) Summer $\left(T_{\max }\right)$

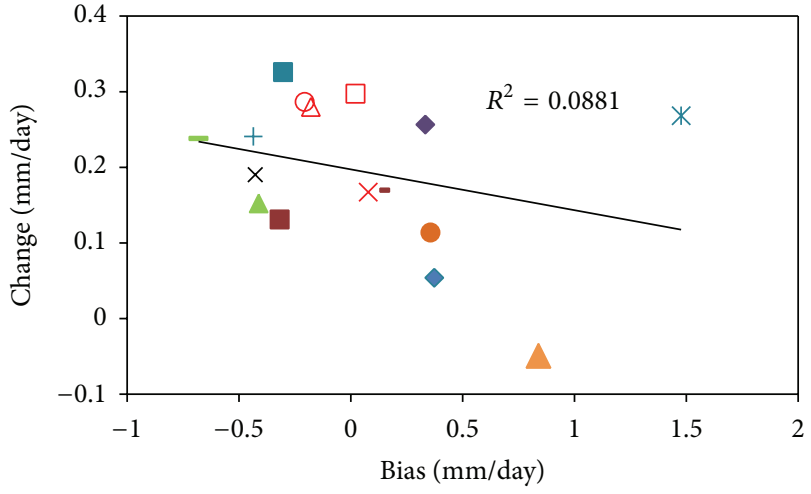

(b) Winter (precipitation)

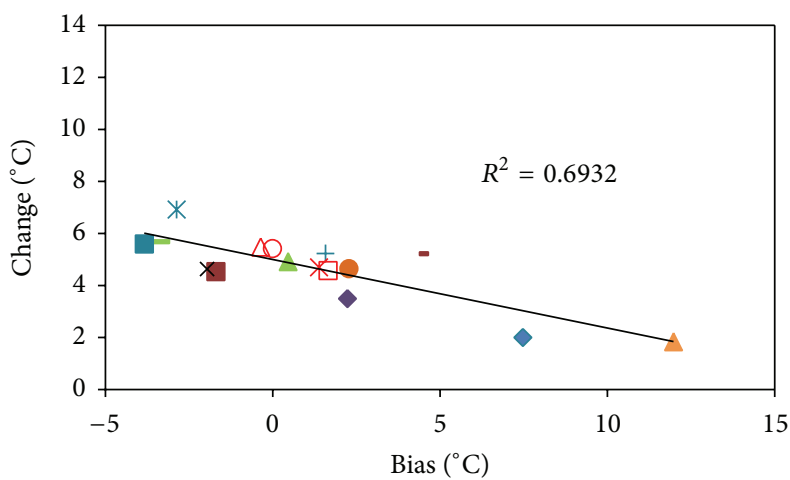

(d) Winter $\left(T_{\min }\right)$

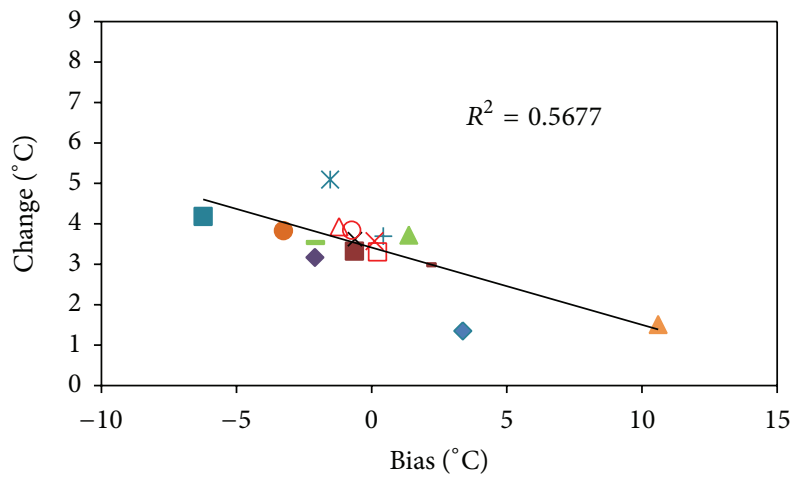
- ARPEGE
o EQ (RCM/AOGCM)
+ CRCM420_CCSM
$\times$ Ensemble_mean
- CRCM420_CGCM3
- MM5I_CCSM
$\triangle \mathrm{DE}(\mathrm{RCM} / \mathrm{AOGCM})$
$\triangle$ CRCM411QC_CGCM3
- WRFG_CCSM
$\times$ CRCM423(AET)_CGCM3
- RCM3 GFDL
$\square$ SEP
* CRCM423(AEV)_CGCM3
ECP2 GFDL
- RCM3_CGCM3
- HRM3_HadCM3

(f) Winter $\left(T_{\max }\right)$

Figure 4: Seasonal (summer and winter, left and right panels, resp.) scatter plots of intermodel and synthetic data of mean change ( $y$-axis) versus bias ( $x$-axis) for the mean precipitation ((a) and (b) panels) and the minimum ((c) and (d) panels) and maximum ((e) and (f) panels) temperatures: all values are spatially averaged over the study area. 


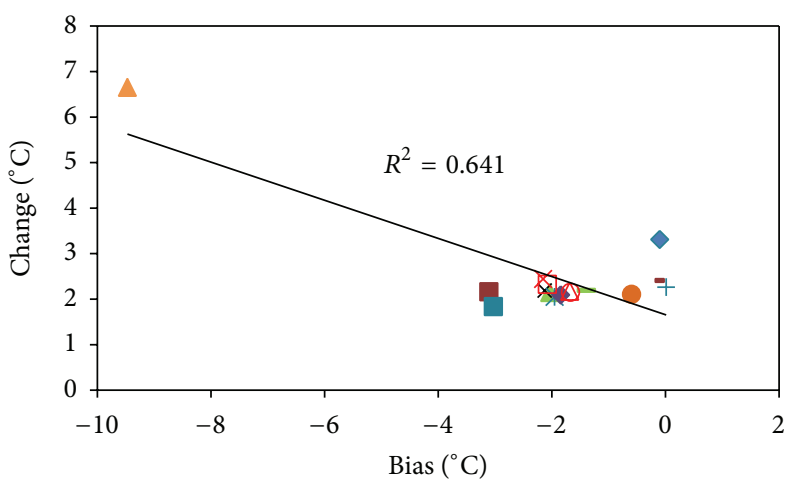

(a) Summer $\left(T_{\min }\right)$

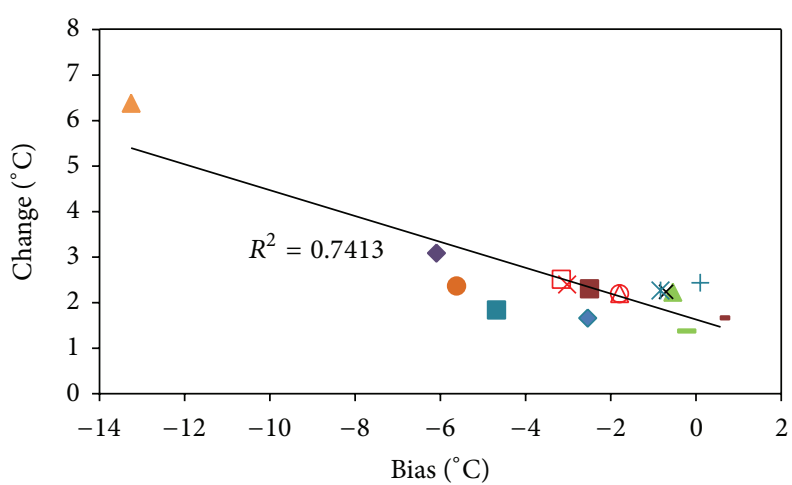

- ARPEGE

+ CRCM420_CCSM

$\times$ Ensemble_mean

- CRCM420_CGCM3

- MM5I_CCSM

$\triangle \mathrm{DE}(\mathrm{RCM} / \mathrm{AOGCM})$

$\triangle$ CRCM411QC_CGCM3

- WRFG_CCSM

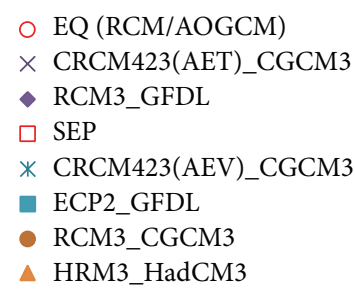

(c) Summer $\left(T_{\max }\right)$

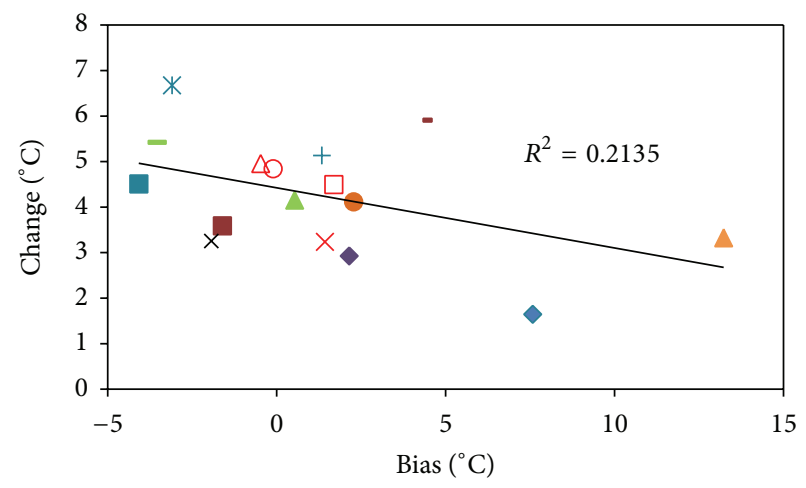

(b) Winter $\left(T_{\min }\right)$

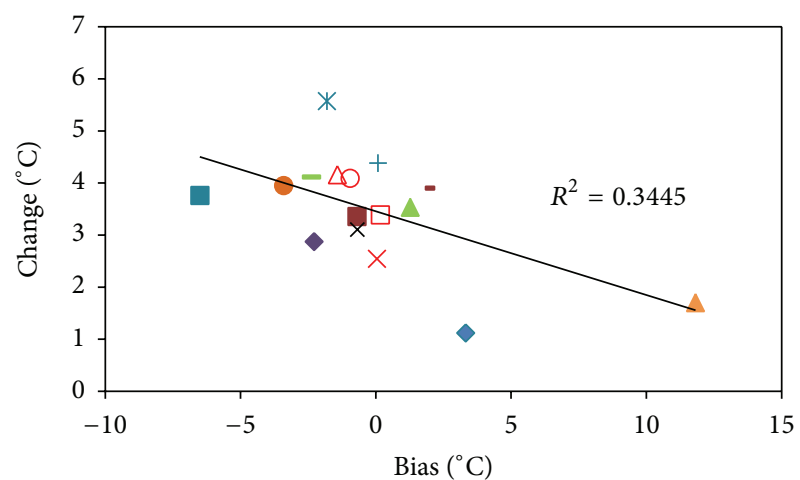

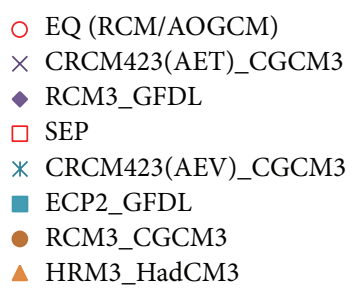

Winter $\left(T_{\max }\right)$

Figure 5: Same as Figure 4 but for the 10th percentile of $T_{\min }$ and $T_{\max }$.

summer and winter, as suggested in Table 2. For $T_{\min }$, the correlation between the 10th percentile change and bias for winter was not significant, whereas the other cases, for example, 10th percentile for summer and 90th percentile changes for summer and winter, showed strong correlations. This suggests that the cold extreme $T_{\min }$ in winter may be dominated by large-scale patterns rather than by the regional physical processes in RCMs. For $T_{\max }$, there were strong correlations, except for the 90th percentile change versus bias for winter. Furthermore, the dependence of the extreme temperature change to model bias in summer was much stronger than in winter, although the correlation between mean change and bias in winter was more significant for the warm extreme of $T_{\min }$. Model bias had a significant effect on the future mean and extremes of $T_{\min }$ and $T_{\max }$, indicating that climate signals in mean values and various ranges of the extremes for both $T_{\min }$ and $T_{\max }$ were significantly and systematically affected by local physical processes such as topography and surface conditions, that is, sub-grid-scale processes. In addition, as shown by the mean changes in Figure 4, the extreme temperature changes in the synthetic data had a narrower range and less bias as compared to the RCM/AOGCM simulations, as expected. This implies that the synthetic scenarios may reduce future climate variability among model runs (i.e., a lower level of uncertainty in the future climate) with improved skill. As noted for the mean precipitation and $T_{\min }$, the DE or EQ synthetic scenarios projected higher signals in the 10th percentile of $T_{\min }$ and $T_{\max }$ than those from the ensemble mean or SEP equivalent values in winter.

\subsection{Comparison of Seasonal Climate Change Signals between} Median and Extreme Values. As noted in the recent IPCC report [6], large changes in extreme values relative to the mean change are projected in the future. Therefore, we examined the climate change signals of extreme values (90th percentile for precipitation; 90 th and 10th percentiles for both $T_{\max }$ and $T_{\min }$ ) with respect to the median values to determine the respective rate of change among median/extreme values 


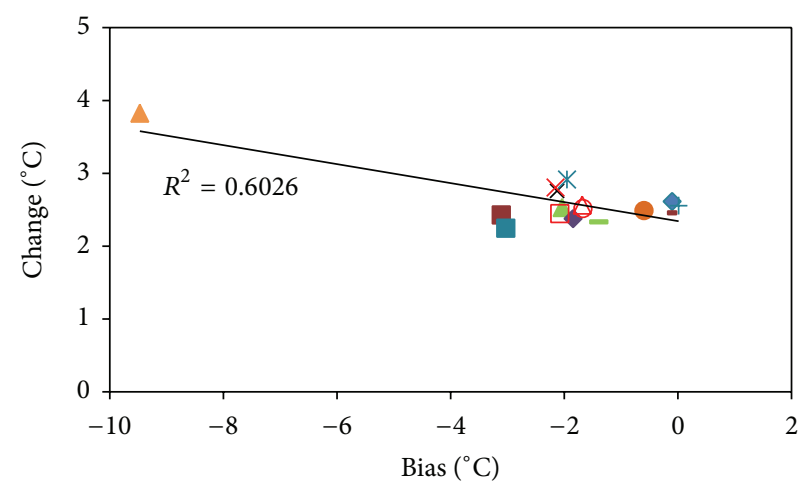

(a) Summer $\left(T_{\min }\right)$

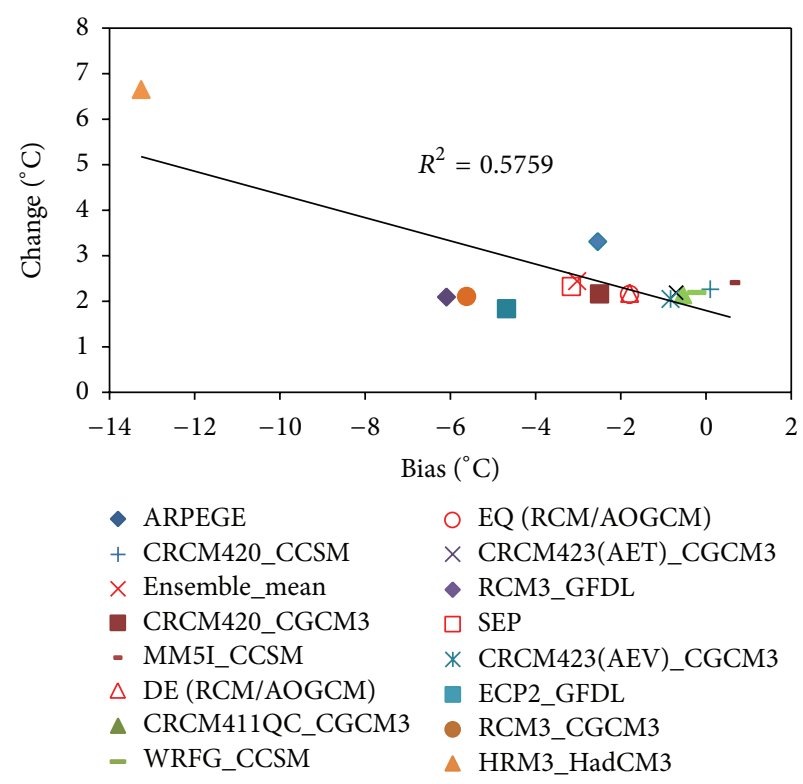

(c) Summer $\left(T_{\max }\right)$

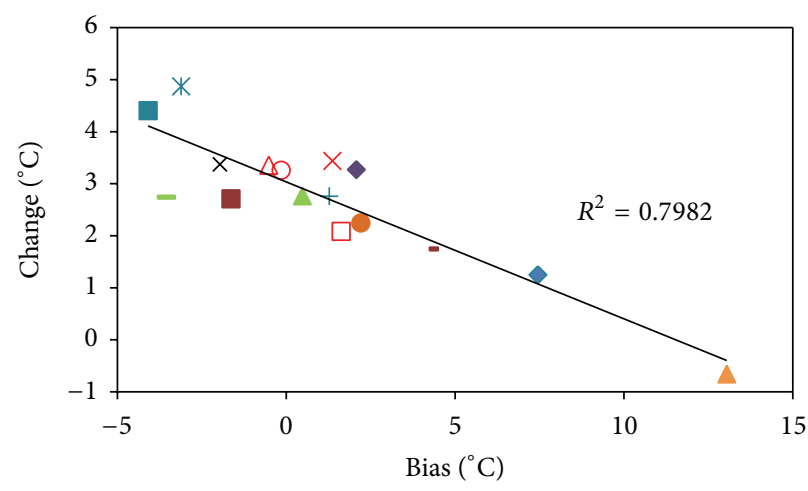

(b) Winter $\left(T_{\min }\right)$
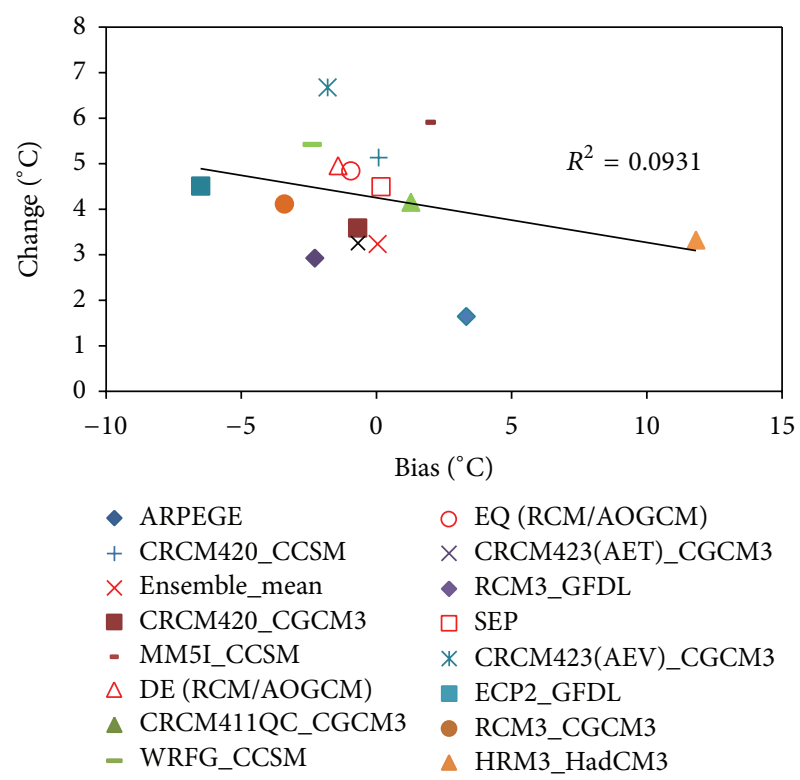

(d) Winter $\left(T_{\max }\right)$

FIgURE 6: Same as Figure 4 but for the 90th percentile of $T_{\min }$ and $T_{\max }$.

over the study region. Note that the signals were rescaled as percentages for precipitation and absolute values (i.e., ${ }^{\circ} \mathrm{C}$ ) for $T_{\min }$ and $T_{\max }$.

Figure 7 shows the seasonal (summer and winter) climate change signal of the models and synthetic data for the 50th $(x-$ axis) and 90th percentile ( $y$-axis) values over the study area. For precipitation change, most RCM/AOGCM simulations projected an increase in both extreme and median values in summer and winter. In most cases, the change in the 90th percentile was larger than that in the median values, especially in winter, when the 90th percentile changes were about twice as large as the 50th percentile changes. This suggests that the frequency of extreme precipitation events may increase more rapidly than the mean change in summer and winter in the future, mainly due to the effects of global warming that accelerates local convection, with an enhancement in humidity in the air and the recycling of water, reaching a higher intensity than that experienced over the historical period, as also noted in [2]. The range of changes for the $12 \mathrm{RCM} / \mathrm{AOGCM}$ simulations was much wider than for the 2 synthetic simulations (DE (RCM/AOGCM) and EQ (RCM/AOGCM)), which incorporated weighting factors into the generation of future climate projections, enabling the more frequent selection of RCM/GCMs with a higher accuracy. In addition, the changes in the two synthetic climate scenarios were very similar to each other, which may indicate a reduction in future variability among models (or less pronounced uncertainty), with respect to raw RCM/AOGCM's simulations, as suggested in [2].

All of the simulations in this study projected an increase in the 50th and 90th percentile values for $T_{\text {min }}$, with a similar rate of changes in summer, that is, most points were located on the diagonal line. There was a small increase in the warm extreme (90th percentile) of $T_{\min }$ and $T_{\max }$ in winter. However, a quasisystematic higher increase in the warm extreme than in the median value of $T_{\max }$ was projected for summer, except in HRM3_HadCM3, which was an outlier among 


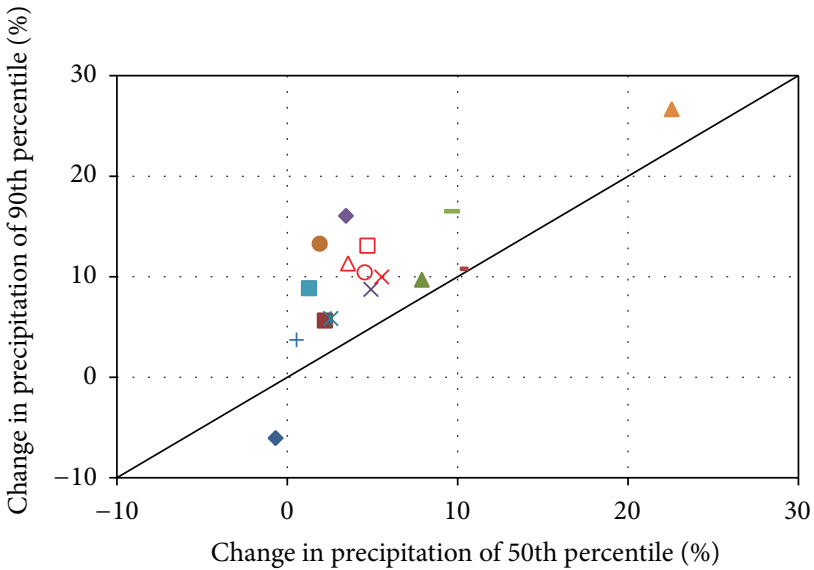

(a) Summer (precipitation)

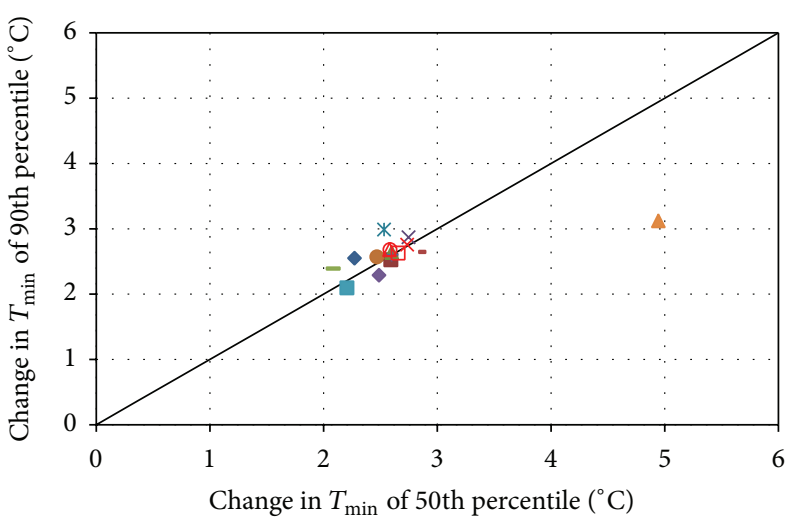

(c) Summer $\left(T_{\min }\right)$

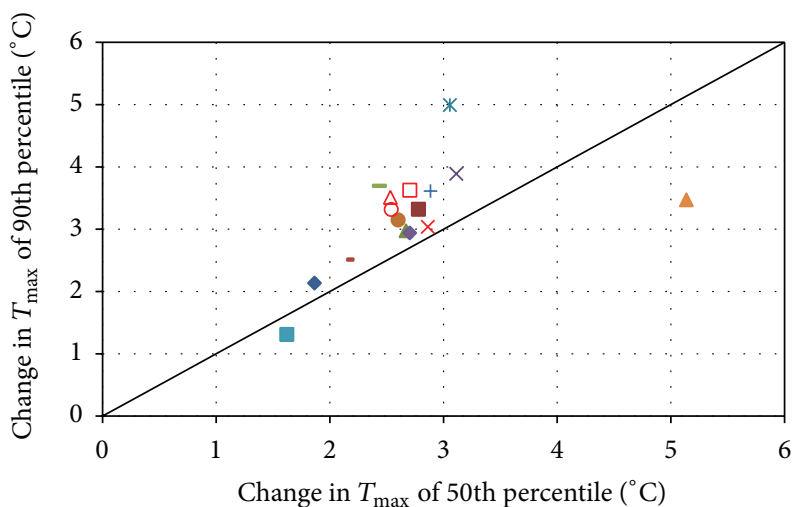

- ARPEGE

+ CRCM420_CCSM

$\times$ Ensemble_mean

- CRCM420_CGCM3

- MM5I_CCSM

$\triangle \mathrm{DE}(\mathrm{RCM} / \mathrm{AOGCM})$

$\triangle$ CRCM411QC_CGCM3

- WRFG_CCSM

EQ (RCM/AOGCM)

$\times$ CRCM423(AET)_CGCM3

- RCM3_GFDL

$\square$ SEP

* CRCM423(AEV)_CGCM3

ECP2_GFDL

- RCM3 CGCM3

A HRM3_HadCM3

(e) Summer $\left(T_{\max }\right)$

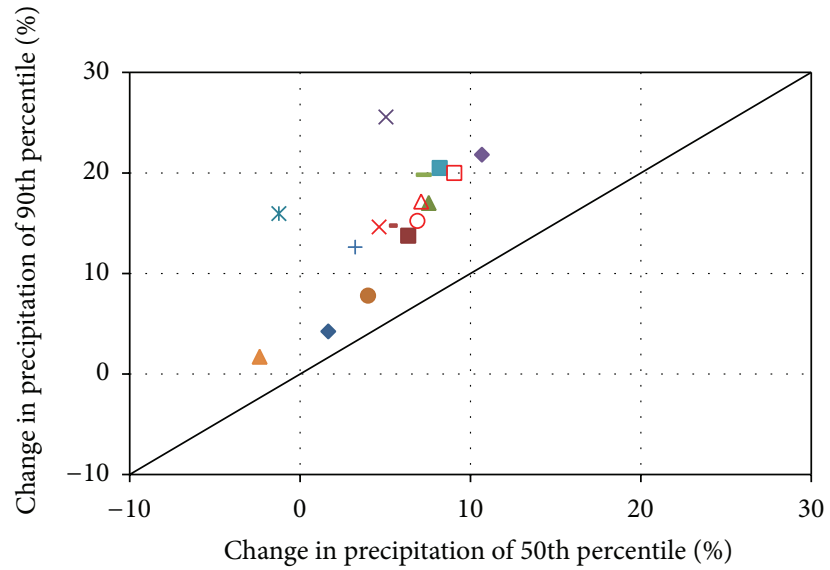

(b) Winter (precipitation)

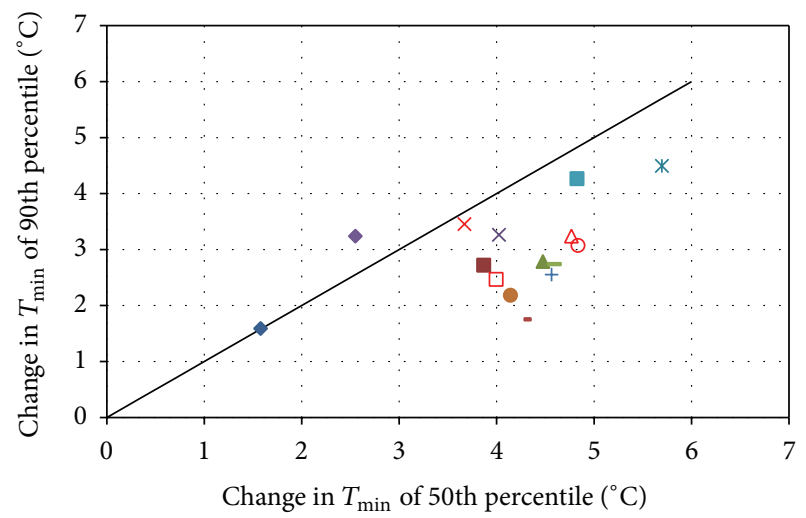

(d) Winter $\left(T_{\min }\right)$

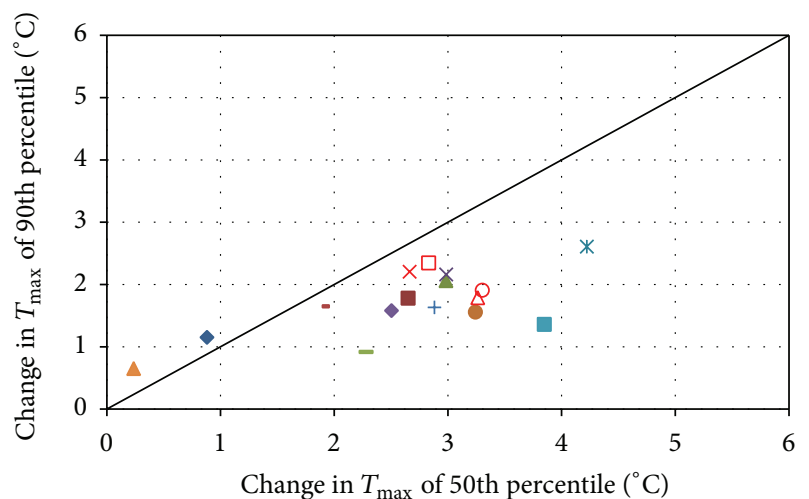

- ARPEGE O EQ (RCM/AOGCM)

+ CRCM420_CCSM $\times$ CRCM423(AET)_CGCM3

$\times$ Ensemble_mean $\quad$ RCM3_GFDL

C CRCM420_CGCM3 $\square$ SEP

- MM5I_CCSM $\quad$ * CRCM423(AEV)_CGCM3

$\triangle \mathrm{DE}(\mathrm{RCM} / \mathrm{AOGCM}) \square \mathrm{ECP} 2 \mathrm{GFDL}$

$\triangle$ CRCM411QC_CGCM3 • RCM3_CGCM3

- WRFG_CCSM $\quad$ A HRM3_HadCM3

(f) Winter $\left(T_{\max }\right)$

FIGURE 7: Seasonal (summer and winter, left and right panels, resp.) scatter plots of intermodel climate change signal of the 50th ( $x$-axis) and 90th ( $y$-axis) percentile values for precipitation ((a) and (b) panels) and minimum ((c) and (d) panels) and maximum ((e) and (f) panels) temperatures: all values are spatially averaged over the study area. 


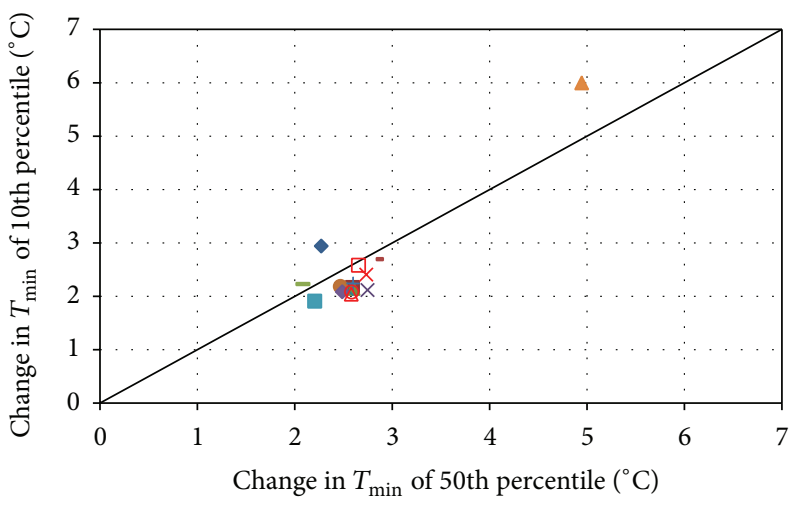

(a) Summer $\left(T_{\min }\right)$

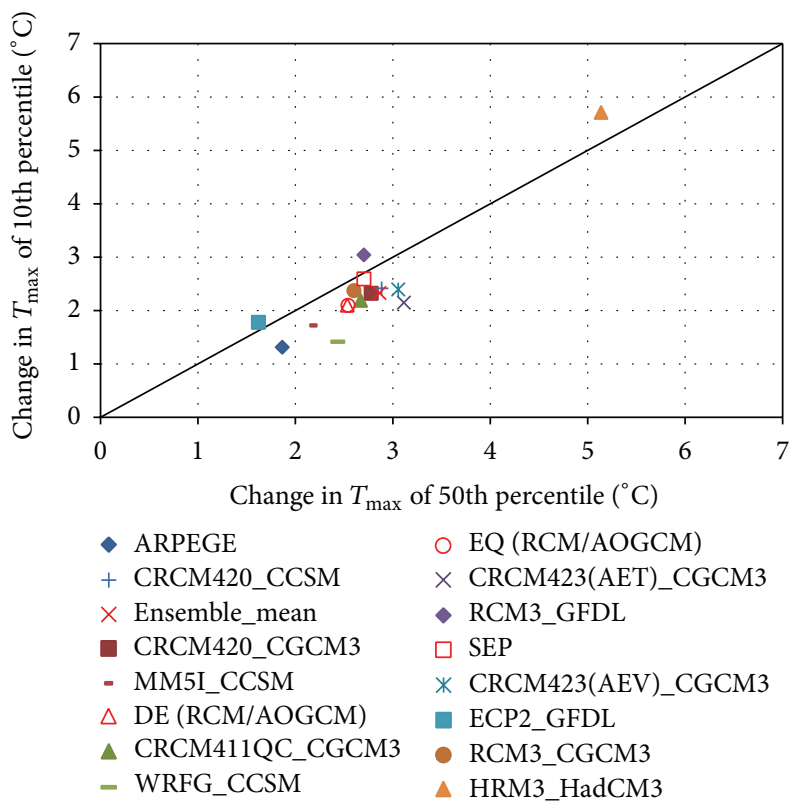

(c) Summer $\left(T_{\max }\right)$

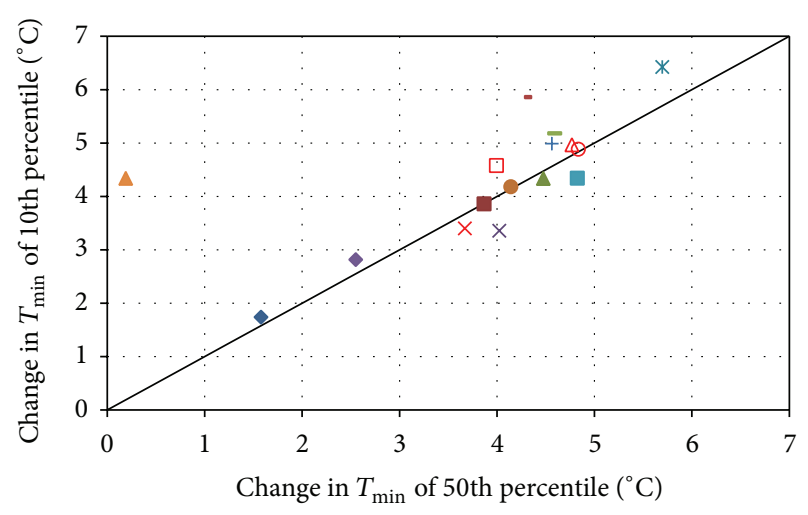

(b) Winter $\left(T_{\min }\right)$

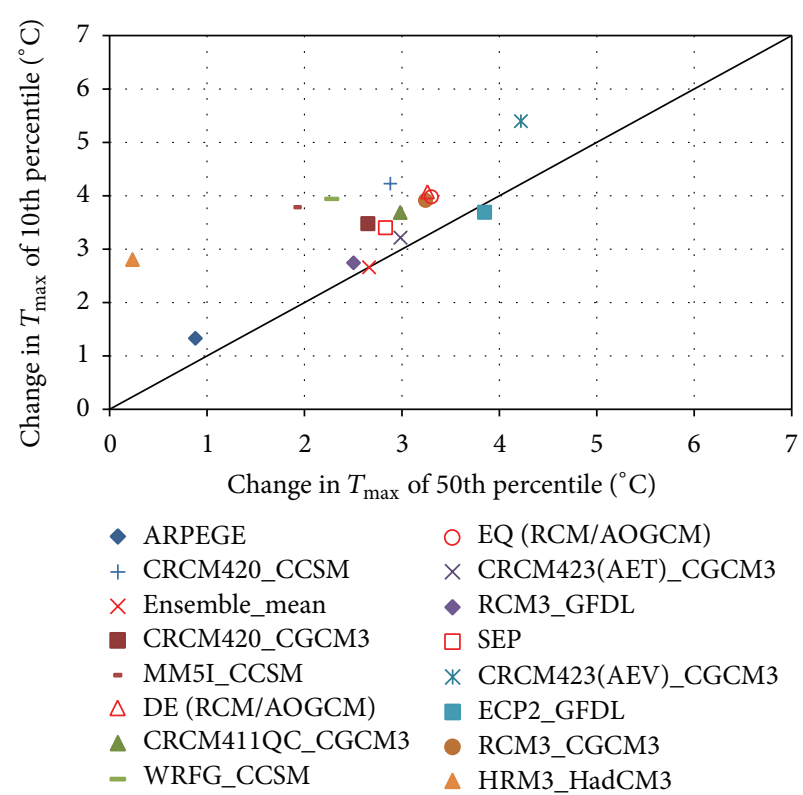

(d) Winter $\left(T_{\max }\right)$

FIgURE 8: Same as Figure 7 but for the 50th ( $x$-axis) and 10th ( $y$-axis) percentile values of $T_{\min }$ and $T_{\max }$.

the RCMs. These results indicate that global warming may affect the mean change more significantly than the extreme hot $T_{\min }$ and $T_{\max }$ in winter. However, the impacts of climate change on extreme temperature may depend on topographic complexity (e.g., mountainous regions; see the suggested warming amplification in high-elevation regions in [40] and dry or wet surface conditions). Consequently, the relative changes need to be investigated in a variety of regions with different physiographic features. Of the 12 RCM/AOGCM simulations, the HRM3_HadCM3 projected the greatest positive change in both the 50th and 90th percentile values for $T_{\min }$ and the highest positive change in both 50th percentile values for $T_{\max }$, but negligible changes were projected in $T_{\min }$ and $T_{\max }$ for winter. The range of changes in $T_{\min }$ for summer was much narrower (i.e., less uncertainty) than for winter. The change ratios for $T_{\min }$ and $T_{\max }$ in the four subzones were similar to each other, although for precipitation a larger change ratio was projected in the north (not shown here). This indicates that the spatial variability of $T_{\min }$ and $T_{\max }$ changes was less pronounced than that for precipitation because these variables were generally more strongly affected by both large scale and regional scale forcings. As with the mean precipitation change, the range of changes for synthetic climate scenarios was narrower than that of the 12 RCM/AOGCM simulations. The DE and EQ scenarios produced higher median values of $T_{\min }$ and $T_{\max }$ in winter than ensemble mean values (i.e., less conservative in this last case).

Figure 8 shows the seasonal (summer and winter) climate change signals of $T_{\min }$ and $T_{\max }$ between the 50th ( $x$-axis) and 10th ( $y$-axis) percentiles for the models and synthetic climate scenarios. In contrast to the warm extremes $T_{\min } / T_{\max }$, the increase in the 10th percentile (mainly $T_{\max }$ ) for the winter was systematically higher than the increase in the 50th percentile in most cases. This indicates that future cold extremes of temperature may be considerably attenuated under climate change conditions. Remarkably, this was not reflected in the winter changes of the ensemble mean scenario, where the changes in the 10th and 50th percentiles for $T_{\min }$ and $T_{\max }$ 


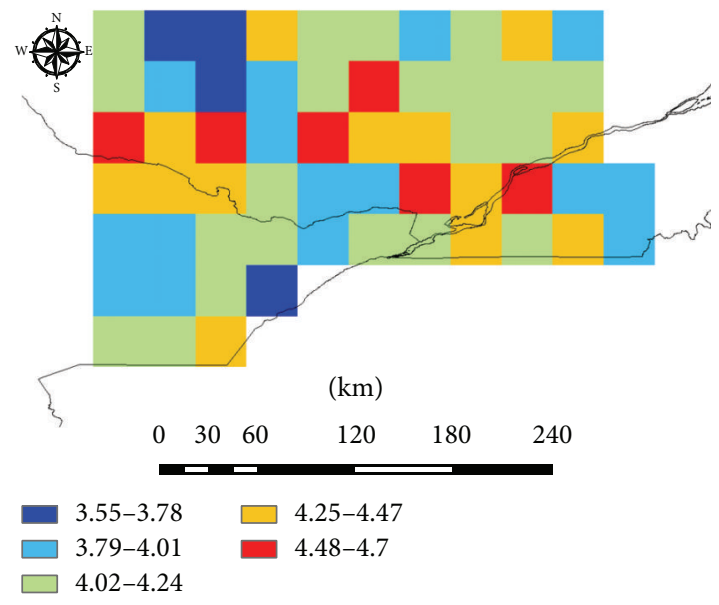

(a) DE (RCM/AOGCM)

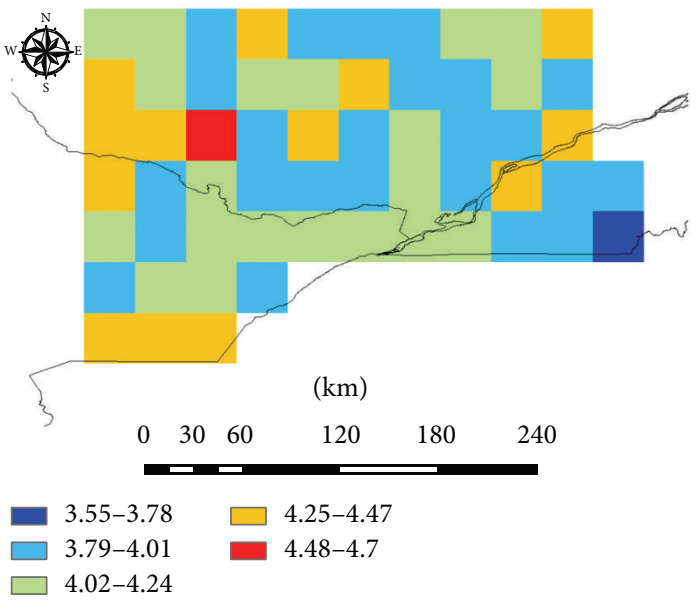

(b) EQ (RCM/AOGCM)

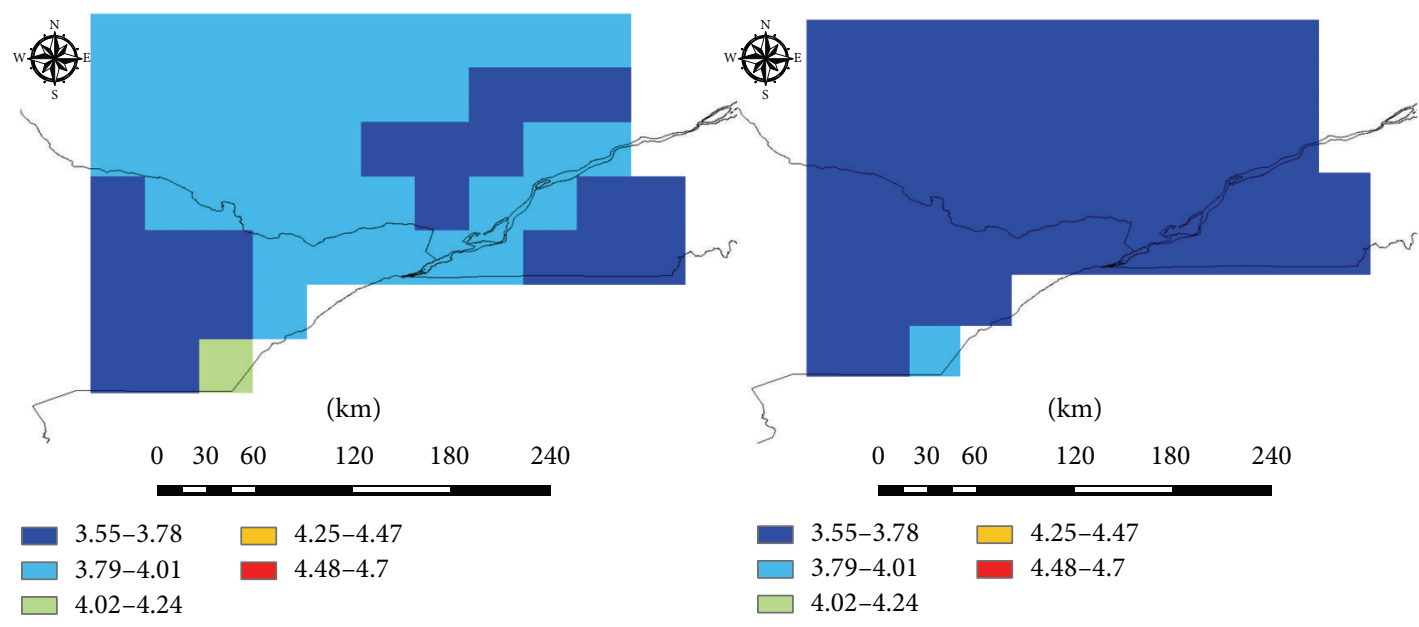

(c) SEP

(d) Ensemble mean

FIGURE 9: Climate change signal of the 10th percentile values at all grid points within the study area for $T_{\max }$ from DE (RCM/AOGCM), EQ (RCM/AOGCM), SEP, and the ensemble mean.

were systematically smaller than those of the DE, EQ, and SEP synthetic scenarios.

Figure 9 provides spatial maps of the 10th percentile $T_{\min }$ signal in winter to illustrate how well the synthetic scenarios capture a range of extreme cold projections. The range of climate change signals for the DE (RCM/AOGCM) and EQ (RCM/AOGCM) synthetic scenarios was much wider than that for SEP and the ensemble mean. The climate change signal of the ensemble mean was restricted to the 3.55$3.78^{\circ} \mathrm{C}$ range, with a smoothing pattern from the averaging process. In Figures 9(a) and 9(b), the areas in the north had relatively greater spatial variability in the 10 th percentile $T_{\min }$ signal for winter, whereas Figures $9(\mathrm{c})$ and $9(\mathrm{~d})$ show a less warm signal. This demonstrates that the synthetic scenarios better capture the spatial variability in cold extreme events from multiple RCM/AOGCM simulations than they do from the ensemble mean scenario, which may provide a more conservative change value because it simply averages all of the RCM/AOGCM simulations.

\section{Summary and Concluding Remarks}

This study investigated the relationship between climate change signals and biases for RCM/AOGCM simulations to assess the dependence of future projections on regional model biases for precipitation, $T_{\min }$, and $T_{\max }$ over southern Québec (Canada). In addition, we compared 16 projections (i.e., 12 RCM/AOGCM's simulations, the ensemble mean, and 3 synthetic simulations) and considered the median and extreme seasonal climate change signals.

For precipitation, among the $12 \mathrm{RCM} / \mathrm{AOGCM}$ combinations tested, we found that the linear dependence of the climate change signal on the model bias was not significant in most cases for either the mean or the extreme values, indicating that precipitation projection is mainly affected by emission scenarios or large-scale forcings in combination or in interaction with various local effects such as topography and local convection. However, for $T_{\min }$ and $T_{\text {max }}$, extreme temperature changes (e.g., the 10th and 90th 
percentiles) for summer and winter depended significantly and systematically on the model bias, except for the warm extreme $T_{\max }$ (90th percentile) and cold extreme $T_{\min }$ (10th percentile) in winter. These results suggest that extreme hot and cold temperatures could be significantly affected by a large-scale forcing derived from boundary conditions, that is, the sensitivity of an RCM/AOGCMs, rather than systematic biases in the RCMs over the study area. In addition, the dependence of modest temperature changes (e.g., the mean change in $T_{\min }$ and 10th percentile change of $T_{\max }$ ) on model bias was significant in all seasons in the study area. The correlation between model bias and mean change was stronger in winter than summer, while the dependence of extreme temperature changes (10th and 90th percentiles) on model bias was stronger in summer than winter. This means that projections of mean winter temperature and summer $T_{\min } / T_{\max }$ extremes may be significantly affected by model bias (i.e., local physical processes) within the study area. Furthermore, the four synthetic scenarios (ensemble mean, DE (RCM/AOGCM), EQ (RCM/AOGCM), and SEP) generated by the MCS technique based on each RCM/AOGCM's skill displayed systematically less bias and a narrower range of mean change for all variables (less uncertainty) compared with raw RCM/AOGCM simulations.

Regarding the climate change signals of median and extreme values, the increased percentage of extremes (90th percentile) was larger than that of median values for precipitation due to the higher air temperature, which accelerated local convection and the water cycle, whereas the increase in the 90th percentile of both $T_{\min }$ and $T_{\max }$ changes was similar to that in the 50th percentile, except in summer, where the hottest temperatures were projected to increase more than the median $T_{\max }$ values. This indicates that more extreme precipitation events and a larger increase in mean temperature may be expected during summer and winter in the future in southern Québec. Nevertheless, the increase in the 10th percentile of both $T_{\min }$ and $T_{\max }$ for winter was larger than that in the 50th percentile, indicating that future cold extremes may be attenuated or reduced by global warming. The range of changes in the signal for the 12 RCM/AOGCM simulations was much greater than the corresponding range for the synthetic scenarios. Furthermore, the changes in the 10th and 50th percentiles of $T_{\min }$ and $T_{\max }$ from the ensemble mean scenario for winter were systematically smaller than those of the synthetic scenarios. These results indicate that the consistency in climate projections may be significantly improved by incorporating the weighting factors assigned from RCM/AOGCM skill. Moreover, we found that the synthetic scenarios (i.e., DE, EQ, and SEP) might provide or develop spatial variability for cold extreme events, whereas the ensemble mean was likely to be too conservative due to the averaging of all RCM/AOGCM simulations.

Although a significant bias-signal correlation was detected for $T_{\min }$ and $T_{\max }$ in this study, a greater number of RCM/AOGCM combinations is required to confirm the effect of model bias introduced by the different skills of RCM/AOGCM combinations. As noted in previous studies $[2,6,19,38]$, when RCMs are forced with different boundary conditions from various AOGCMs, the systematic biases of AOGCMs may affect the skill of RCM/AOGCM combinations. Even when RCMs were forced by a specific AOGCM, the bias patterns (not shown) differed from one RCM to another, implying a wider spread across the ensemble of RCMs $[13,19,41]$. Incorporating a larger pool of RCM/AOGCM's simulations, as undertaken in the recent the COordinated Regional climate Downscaling Experiment initiative (CORDEX; Giorgi et al. [42]; http://wcrp-cordex.ipsl .jussieu.fr), may provide a more comprehensive insight into the relationships between bias and climate change signals, especially for extreme values at the regional scale.

\section{Conflict of Interests}

The authors declare that there is no conflict of interests regarding the publication of this paper.

\section{Acknowledgments}

This research was made possible by a financial support from Québec's Ministère du Développement Économique, de l'Innovation et de l'Exportation (MDEIE), National Sciences and Engineering Research Council (NSERC) of Canada, and partially APEC Climate Center (APCC) and a grant (14AWMP-B082564-01) from Advanced Water Management Research Program funded by Ministry of Land, Infrastructure and Transport of the Korean government. The authors would like to acknowledge the Data Access and Integration (DAI, see http://climat-quebec.qc.ca/CC-DEV/trunk/ index.php/pages/dai) Team for providing the data and technical support, in particular the help of Milka Radojevic in preparing the data. The DAI data download gateway is made possible through collaboration among the FQRNT-funded Global Environmental and Climate Change Centre (GEC3), the Adaptation and Impacts Research Section (AIRS) of Environment Canada, and the Drought Research Initiative (DRI). The CRCM time series data has been generated and supplied by Ouranos' Climate Simulations Team. We wish to thank the North American Regional Climate Change Assessment Program (NARCCAP) for providing the data used in this paper. NARCCAP is funded by the National Science Foundation (NSF), the U.S. Department of Energy (DoE), the National Oceanic and Atmospheric Administration (NOAA), and the U.S. Environmental Protection Agency Office of Research and Development (EPA).

\section{References}

[1] A. F. Hamlet and D. P. Lettenmaier, "Effects of 20th century warming and climate variability on flood risk in the western US," Water Resources Research, vol. 43, no. 6, Article ID W06427, 2007.

[2] H.-I. Eum, P. Gachon, and R. Laprise, "Developing a likely climate scenario from multiple regional climate model simulations with an optimal weighting factor," Climate Dynamics, vol. 43, no. 1-2, pp. 11-35, 2014.

[3] L. A. Vincent, X. L. Wang, E. J. Milewska, H. Wan, F. Yang, and V. Swail, "A second generation of homogenized Canadian monthly surface air temperature for climate trend analysis," Journal of 
Geophysical Research: Atmospheres, vol. 117, no. 17, Article ID D18110, 2012.

[4] CCSP, Weather and Climate Extremes in a Changing Climate, NOAA's National Climate Data Center, Washington, DC, USA, 2008.

[5] B. R. Bonsal, R. Aider, P. Gachon, and S. Lapp, "An assessment of Canadian prairie drought: past, present, and future," Climate Dynamics, vol. 41, no. 2, pp. 501-516, 2013.

[6] IPCC, Managing the Risks of Extreme Events and Disasters to Advance Climate Change Adaptation, A Special Report of Working Groups I and II of the Intergovernmental Panel on Climate Change, Cambridge University Press, Cambridge, UK, 2012, edited by: C. B. Field, V. Barros, T. F. Stocker, D. Qin, D. J. Dokken, K. L. Ebi, M. D. Mastrandrea, K. J. Mach, G.-K. Plattner, S. K. Allen, M. Tignor, P. M.

[7] L. R. Leung and S. J. Ghan, "Pacific Northwest climate sensitivity simulated by a regional climate model driven by a GCM. Part II: $2 \times \mathrm{CO}_{2}$ simulations," Journal of Climate, vol. 12, no. 7, pp. 20312053, 1999.

[8] P. van der and J. F. B. Linden, ENSEMBLES: Climate Change and its Impacts: Summary of Research and Results from the ENSEMBLES Project, Met Office Hadley Centre, Exeter, UK, 2009.

[9] D. Jacob, A. Elizalde, A. Haensler et al., "Assessing the transferability of the regional climate model REMO to different coordinated regional climate downscalilng experiment (CORDEX) regions," Atmosphere, vol. 3, no. 1, pp. 181-199, 2012.

[10] P. B. Duffy, R. W. Arritt, J. Coquard et al., "Simulations of present and future climates in the western United States with four nested regional climate models," Journal of Climate, vol. 19, no. 6, pp. 873-895, 2006.

[11] P. Gachon and Y. Dibike, "Temperature change signals in northern Canada: convergence of statistical downscaling results using two driving GCMs," International Journal of Climatology, vol. 27, no. 12, pp. 1623-1641, 2007.

[12] J. H. Christensen, T. R. Carter, M. Rummukainen, and G. Amanatidis, "Evaluating the performance and utility of regional climate models: the PRUDENCE project," Climatic Change, vol. 81, supplement 1, pp. 1-6, 2007.

[13] D. Jacob, J. Petersen, B. Eggert et al., "EURO-CORDEX: new high-resolution climate change projections for European impact research," Regional Environmental Change, vol. 14, no. 2, pp. 563-578, 2014.

[14] H. Visser, R. J. M. Folkert, J. Hoekstra, and J. J. de Wolff, "Identifying key sources of uncertainty in climate change projections," Climatic Change, vol. 45, no. 3-4, pp. 421-457, 2000.

[15] H. J. Fowler and M. Ekström, "Multi-model ensemble estimates of climate change impacts on UK seasonal precipitation extremes," International Journal of Climatology, vol. 29, no. 3, pp. 385-416, 2009.

[16] F. Giorgi and E. Coppola, "Does the model regional bias affect the projected regional climate change? An analysis of global model projections: a letter," Climatic Change, vol. 100, no. 3, pp. 787-795, 2010.

[17] J. H. Christensen, T. R. Carter, and F. Giorgi, "PRUDENCE employs new methods to assess european climate change," Eos, vol. 83, no. 13, p. 147, 2002.

[18] L. O. Mearns, W. J. Gutowski, R. Jones et al., "A regional climate change assessment program for North America," EOS Transactions, vol. 90, no. 36, pp. 311-312, 2012.
[19] J. H. Christensen, E. Kjellström, F. Giorgi, G. Lenderink, and M. Rummukainen, "Weight assignment in regional climate models," Climate Research, vol. 44, no. 2-3, pp. 179-194, 2010.

[20] E. Coppola, F. Giorgi, S. A. Rauscher, and C. Piani, "Model weighting based on mesoscale structures in precipitation and temperature in an ensemble of regional climate models," Climate Research, vol. 44, no. 2-3, pp. 121-134, 2010.

[21] J. Räisänen and J. S. Ylhäisi, "Can model weighting improve probabilistic projections of climate change?" Climate Dynamics, vol. 39, no. 7-8, pp. 1981-1998, 2012.

[22] H.-I. Eum, P. Gachon, R. Laprise, and T. Ouarda, "Evaluation of regional climate model simulations versus gridded observed and regional reanalysis products using a combined weighting scheme," Climate Dynamics, vol. 38, no. 7-8, pp. 1433-1457, 2012.

[23] D. Caya and R. Laprise, "A semi-implicit semi-Lagrangian regional climate model: the Canadian RCM," Monthly Weather Review, vol. 127, no. 2-3, pp. 341-362, 1999.

[24] R. Laprise, D. Caya, A. Frigon, and D. Paquin, "Current and perturbed climate as simulated by the second-generation Canadian Regional Climate Model (CRCM-II) over northwestern North America," Climate Dynamics, vol. 21, no. 5-6, pp. 405-421, 2003.

[25] N. Nakicenovic, J. Alcamo, G. Davis et al., IPCC Special Report on Emissions Scenarios, Cambridge University Press, Cambridge, UK, 2000.

[26] M. Déqué and J. P. Piedeliévre, "High resolution climate simulation over Europe," Climate Dynamics, vol. 11, no. 6, pp. 321-339, 1995.

[27] W. D. Collins, C. M. Bitz, M. L. Blackmon et al., "The Community Climate System Model version 3 (CCSM3)," Journal of Climate, vol. 19, no. 11, pp. 2122-2143, 2006.

[28] G. M. Flato and G. J. Boer, "Warming asymmetry in climate change simulations," Geophysical Research Letters, vol. 28, no. 1, pp. 195-198, 2001.

[29] T. L. Delworth, A. J. Broccoli, A. Rosati et al., "GFDL's CM2 global coupled climate models. Part I: formulation and simulation characteristics," Journal of Climate, vol. 19, pp. 643-674, 2006.

[30] C. Gordon, C. Cooper, C. A. Senior et al., "The simulation of SST, sea ice extents and ocean heat transports in a version of the Hadley Centre coupled model without flux adjustments," Climate Dynamics, vol. 16, no. 2-3, pp. 147-168, 2000.

[31] A.-L. Gibelin and M. Déqué, "Anthropogenic climate change over the Mediterranean region simulated by a global variable resolution model," Climate Dynamics, vol. 20, no. 4, pp. 327-339, 2003.

[32] E. Kalnay, M. Kanamitsu, R. Kistler et al., "The NCEP/NCAR 40-year reanalysis project," Bulletin of the American Meteorological Society, vol. 77, no. 3, pp. 437-471, 1996.

[33] S. M. Uppala, P. W. Kållberg, A. J. Simmons et al., “The ERA40 re-analysis," Quarterly Journal of the Royal Meteorological Society, vol. 131, no. 612, pp. 2961-3012, 2005.

[34] K. V. Price, R. M. Storn, and J. A. Lampinen, Differential Evolution: A Practical Approach to Global Optimization, Springer, Berlin, Germany, 2005.

[35] M. F. Hutchinson, D. W. McKenney, K. Lawrence et al., "Development and testing of Canada-wide interpolated spatial models of daily minimum-maximum temperature and precipitation for 1961-2003," Journal of Applied Meteorology and Climatology, vol. 48, no. 4, pp. 725-741, 2009.

[36] M. Cholette, R. Laprise, and J. M. Thériault, "Perspectives for very high-resolution climate simulations with nested models: 
illustration of potential in simulating St. Lawrence River Valley channelling winds with the fifth-generation Canadian regional climate model," Climate, vol. 3, no. 2, pp. 283-307, 2015.

[37] C. Wang, R. Jones, M. Perry, C. Johnson, and P. Clark, “Using ultrahigh-resolution regional climate model to predict local climatology," Quarterly Journal of the Royal Meteorological Society, vol. 139, no. 677, pp. 1964-1976, 2013.

[38] P. Roy, P. Gachon, and R. Laprise, "Sensitivity of seasonal precipitation extremes to model configuration of the Canadian regional climate model over eastern Canada using historical simulations," Climate Dynamics, vol. 43, no. 9, pp. 2431-2453, 2014.

[39] J. H. Christensen, K. Krishna Kumar, E. Aldrian et al., "Climate phenomena and their relevance for future regional climate change," in Climate Change 2013: The Physical Science Basis. Contribution of Working Group I to the Fifth Assessment Report of the Intergovernmental Panel on Climate Change, T. F. Stocker, D. Qin, G.-K. Plattner et al., Eds., Cambridge University Press, Cambridge, UK, 2013.

[40] Q. Wang, X. Fan, and M. Wang, "Recent warming amplification over high elevation regions across the globe," Climate Dynamics, vol. 43, no. 1-2, pp. 87-101, 2014.

[41] C. Jacob, L. Bärring, O. B. Christensen et al., "An intercomparison of regional climate models for Europe: model performance in present-day climate," Climatic Change, vol. 81, supplement 1, pp. 31-52, 2007.

[42] F. Giorgi, C. Jones, and G. R. Asrar, "Addressing climate information needs at the regional level: the CORDEX framework," WMO Bulletin, vol. 58, no. 3, pp. 175-183, 2009. 

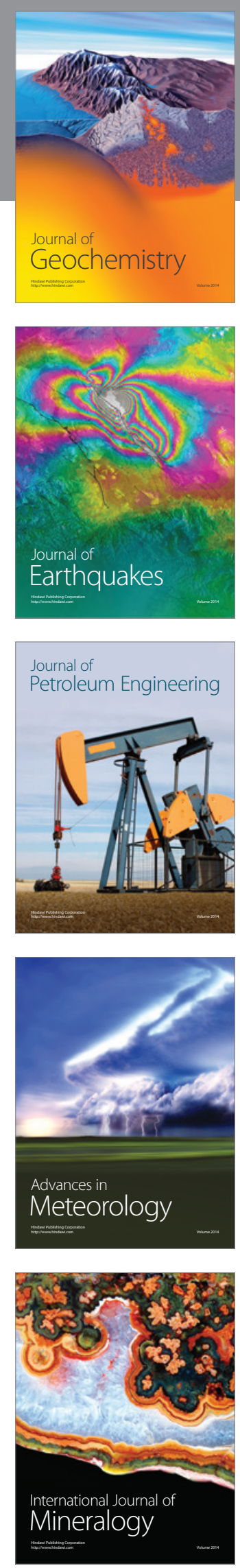
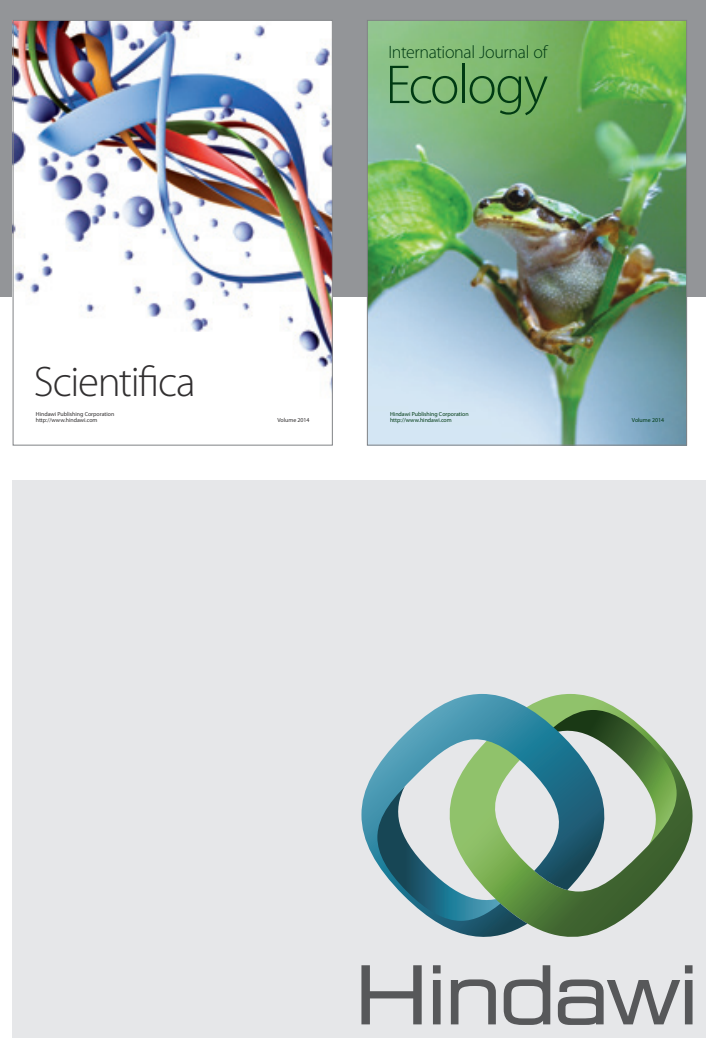

Submit your manuscripts at

http://www.hindawi.com
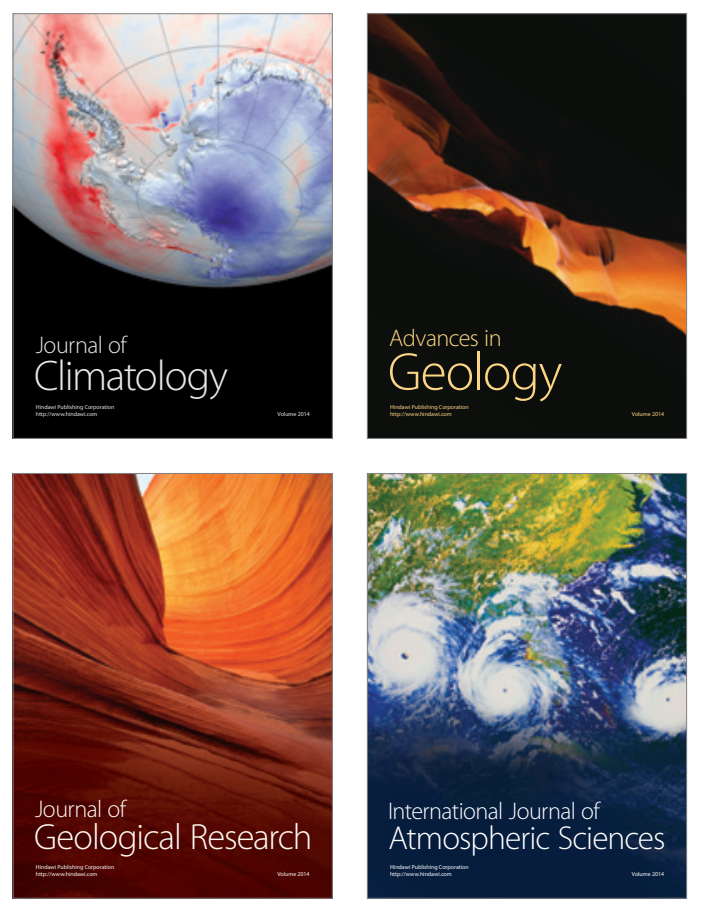

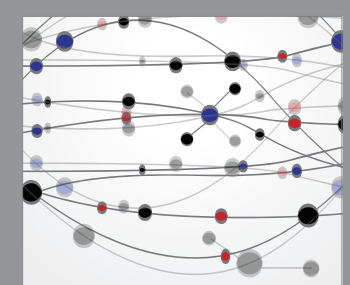

The Scientific

\section{World Journal}
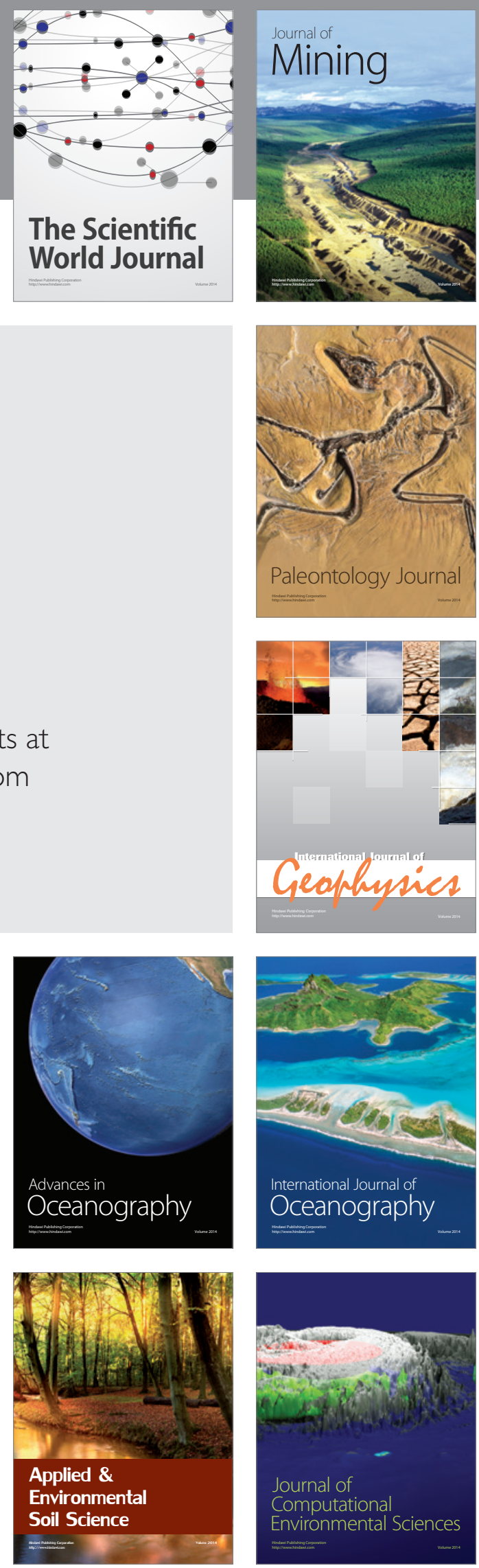